\title{
Pautas de localización de las sedes de las grandes empresas y entornos metropolitanos ${ }^{* *}$
}

\begin{abstract}
Firm headquarter location is of socio-territorial interest since it relates to relations of power and dependence between territories, with a progressive tendency towards globalization. The main objective is to identify some of the socioterritorial factors that determine location, based on the hypothetical importance attached to metropolitan areas and to capital cities. The empirical analysis relates to the decision-making centers of large firms and at the level of subsidiary decision-making centers for secondary states (Spain). By doing this, the worldwide scale of large multinational companies will be compared with the performance of secondary territories, with regards to the distribution of main and subsidiary headquarters. The empirical base includes the 500 largest firms worldwide (fortune, 2005) and the 1000 largest companies in Spain for the secondary territories. The conclusion reached is that territorial concentration of political and economic power and international connections - in this order - are the three fundamental factors behind the decisions made regarding the location of both headquarters and subsidiaries. These are the conditions found almost exclusively in metropolitan areas, and more significantly in capital cities.
\end{abstract}

Keywords: large firms, location, headquarters, metropoli, power relations.

\section{Resumen}

La localización de las sedes de las grandes empresas (headquarter) es un tema de interés socioterritorial por cuanto implica relaciones de poder y dependencia entre territorios, con tendencia progresiva a la mundialización. El objetivo principal es detectar algunos de los factores socioterritoriales que intervienen en su localización, sobre la hipótesis de la importancia que tienen los entornos metropolitanos y de capitalidad. El análisis empírico se plantea al nivel de los centros de decisión de las grandes empresas y al nivel de los centros de decisión subsidiaria en naciones secundarias (España). Así la escala mundial de las grandes empresas multinacionales se contrastará con lo que ocurre dentro de un territorio secundario en las lógicas de distribución de las sedes primarias y subsidiarias. Se toma como base las 500 grandes empresas mundiales (Fortune, 2005) y las 1000 mayores empresas en España para los territorios secundarios. La conclusión es que la concentración territorial de poder político, poder económico y vinculación internacional -por este orden de importancia-, son los tres factores fundamentales que explican las decisiones de localización tanto de sedes centrales como subsidiarias, condiciones que de forma casi exclusiva se dan en las áreas metropolitanas, y con especial significación en las capitales de Estado.

Palabras clave: gran empresa, localización, sede central, metrópolis, relaciones de poder. 


\section{Entornos metropolitanos y localización de los centros de decisión (headquarters) de las grandes empresas}

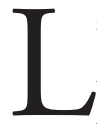

a localización de las sedes de las grandes empresas es un tema de interés socioterritorial por cuanto implica unas relaciones de vasto alcance entre territorios, con tendencia progresiva a la mundialización de estas relaciones en el proceso que se viene denominando de globalización. Estas relaciones no comprometen únicamente a los procesos económicos, sino que se manifiestan como relaciones de poder de trascendencia diversa: de dependencia económica, de dependencia política o de imbricación cultural.

La expansión y amplitud territorial de las actuaciones de estas grandes empresas, que tienen como objetivo fundamental superar sus límites nacionales, las fuerza a una organización territorial compleja en forma piramidal a través de la cual se articulan los canales de poder de decisión, que se concretan en unos nodos territoriales subsidiarios como forma de adaptación entre la estructura multinacional de la empresa y las condiciones jurídicas que cada país (Estado) impone. A nivel de países observaremos una organización subsidiaria de la gran empresa con un subcentro de decisión para cada tipo de actuación.

Es interesante observar que al aumentar la complejidad y polivalencia de producciones en las grandes empresas, éstas pueden actuar sobre un territorio mediante diversas empresas subsidiarias independientes entre sí, a través de las cuales multiplican su capacidad de intervención y su poder ${ }^{1}$.

Departamento de Geografía Humana de la Universidad de Barcelona, Facultad de Geografía e Historia, Barcelona, España. E-mail: jesanchez@ub.edu.

** Este trabajo se encuadra en un extenso proyecto de investigación que ha dado como resultados entre otros las publicaciones: Sánchez, J.-E., 1995; 2006a; 2006b.

Por ejemplo, la empresa Volkswagen actúa en España como fabricante bajo la marca SEAT, pero también como centro productivo de su red mundial en Landaben y como dos organizaciones comerciales para España diferenciadas para sus productos Volkswagen-Audi y Skoda. En este ejemplo observamos cómo una empresa multinacional dispone de cuatro subsidiarias independientes entre sí para un solo Estado-territorio.
Un análisis de la articulación territorial del poder de estas empresas deberá considerar tres grandes niveles de incidencia territorial: a) En cuanto localización de la sede social central y, por tanto, del centro de poder absoluto; b) En cuanto localización de los centros de decisión subsidiarios dentro de cada país; c) En cuanto a los centros de producción y comercialización a través de los que ejecuta sus actividades económicas, distribuidos funcionalmente a escala mundial y dentro de los territorios nacionales. En este trabajo nos centraremos en los dos primeros aspectos, la localización de sedes y subsedes y su vinculación con el hecho metropolitano.

Presuponemos que la decisión de localización de las sedes y subsedes obedece a criterios lógicos y que estos no tienen que ser necesariamente los mismos según se trate de la sede central o de las sedes subsidiarias.

De esta forma analizaremos en primer lugar las vinculaciones territoriales en la localización de las sedes centrales de las grandes empresas y en qué medida influye el hecho metropolitano en ello. El segundo nivel de análisis se centrará en considerar los posibles criterios de localización para el caso de las sedes subsidiarias. Trataremos pues de dos tipos de territorios, aquellos desde los que se ha impulsado la creación de grandes empresas y aquellos, que podemos considerar de segundo nivel, que han atraído el interés para desarrollar parte de su actividad económica. La escala mundo y la escala país constituirán los marcos territoriales empíricos. En este último caso tomaremos a España como unidad territorial de análisis. Al estudiar un solo caso a esta escala únicamente será posible plantear hipótesis de trabajo que deberían verificarse o modificarse a través de otros trabajos empíricos.

Para el análisis de las sedes centrales partiremos del listado de las 500 grandes empresas mundiales publicado por "Fortune" para el año 2005 (edición de 2006). El análisis territorial de segundo nivel tomará en consideración las 1000 mayores empresas jurídicas que actúan en España (Fomento de la Producción, 2005), lo que nos permitirá diferenciar las lógicas de localización de las grandes empresas españolas respecto de las subsidiarias de empresas multinacionales que 
se encuadran entre estas 1000 mayores. Situar el análisis a escala mundo y a escala de país ha de permitirnos contrastar si la lógica de localización de la sedes para las grandes empresas mundiales y para las grandes empresas nacionales siguen las mismas pautas. A su vez la escala país nos sitúa en el ámbito de la lógica de localización de las sedes subsidiarias. Para ambos niveles nuestro objetivo será considerar el hecho metropolitano como factor de localización.

La pretensión de este trabajo es la de establecer un modelo inicial de análisis de localización que debería contrastarse y ajustarse a medida que se disponga de nuevas aproximaciones empíricas a otros entornos metropolitanos.

\section{La búsqueda de elementos de vinculación entre el poder económico y la lógica de formación metropolitana}

Partimos de la premisa de que la secuencia histórica de formación de ámbitos metropolitanos ha sido inducida por los procesos económicos $\mathrm{y}$ por el desarrollo tecnológico, de forma que la metropolización se sustenta en la potenciación territorial de poder económico. En gran número de casos factores políticos como la capitalidad han contribuido a fortalecer su poder económico ${ }^{2}$. En cualquier caso, área metropolitana y poder, como potencia económica o política, son prácticamente inseparables.

En esta línea centraremos la atención en las actividades productivas y económicas, así como en su vinculación con el poder económico y con la escala territorial desde la que éste actúa, de forma que nos permita alcanzar el propósito de evaluar elementos de análisis para avanzar hacia una guía de factores de localización de los centros de decisión empresarial.

\section{Poder y poder económico empresarial}

Es conocida la importancia que tienen los centros de decisión en las relaciones de poder sobre los ámbitos económico, político, ideológico

Un caso de potenciación del poder económico a partir del poder político de capitalidad lo estudié para el caso de Madrid (Ver Sánchez, 1986). y territorial, por lo que la localización específica de estos centros asume evidente trascendencia socioterritorial. Cuando se trata del ámbito de la empresa esta importancia tiene, por lo menos, tres vertientes muy concretas: a) En términos de estructura social, política y económica, donde la gran empresa representa un poder real de intervención, por cuanto con sus políticas particulares específicas afecta tanto a la estructura social global como a las unidades territoriales sobre las que ejerce influencia; b) En la relación entre territorio de decisión y territorio de ejecución productiva, en cuanto las políticas territoriales deben contar con las decisiones que se tomen desde centros situados fuera del territorio de actuación; c) En quién tiene capacidad para adoptar decisiones, $\mathrm{y}$ aquí el papel de la propiedad es fundamental, lo que conlleva plantear la procedencia territorial de los capitales, y en este punto se plantean los temas de la internacionalización y la globalización.

En términos de poder social, la relación entre la capacidad de influencia directa e indirecta de las grandes empresas frente al limitado número de personas que concentran en sus manos este poder -con un elevado porcentaje de poder económicootorga un importante papel a los planteamientos endogámicos -con sus filias y sus fobias- a través de los cuales trasmitir rápida y eficazmente su influencia por el tejido socioterritorial.

\section{Relaciones de dominio y dependencia y localización de los centros de decisión}

Las relaciones de dominio y dependencia adquieren una especial significación desde la vertiente territorial. En primer lugar en la relación de dependencia territorial y jerárquica entre centro de decisión y centro o centros subsidiarios de gestión o ejecución productiva, dado que, sobre todo en el tipo de grandes empresas de que estamos tratando, acostumbra a darse la separación territorial entre ellos, así como una amplia dispersión territorial de unidades productivas. Este tipo de empresas se caracterizan por que las decisiones importantes serán tomadas en un lugar distinto de donde se localizan las unidades de ejecución.

El segundo aspecto de importancia fundamental se refiere a la relación entre lugar de producción 
del valor, y consiguientemente de las plusvalías, y lugar de destino del valor añadido apropiado, sea bajo la forma de distribución de los beneficios o sea sobre las decisiones de su uso como inversión y, más específicamente, sobre el lugar de destino de la inversión. Cómo se reparta el valor añadido, cuánto se destine a la inversión, en qué actividades y, sobre todo, dónde se reinvierta, son aspectos trascendentes desde las perspectivas social y territorial en el estudio entre lugar de producción y lugar de reproducción. La relación territorial entre centros de decisión y centros de ejecución hace de estos últimos lugares subordinados, ya que ven limitada su capacidad autónoma de decisión o no disponen de ella, en aspectos de trascendencia en su relación y vinculaciones con su entorno y con su futuro.

Por ello, la localización de los centros desde donde se toman las decisiones, y sobre todo su concentración en zonas determinadas del territorio se manifiestan como un ámbito esencial de articulación territorial del poder con importantes implicaciones para las zonas en las que se ubican los centros productivos subsidiarios de estas empresas. Aquí es donde entran en juego las grandes ciudades y los contextos metropolitanos.

Aun así, la localización de la sede central debe ser tomada como un punto de referencia relativo, y no absoluto, ya que lo verdaderamente significativo se sitúa en el ámbito de la territorialidad del accionariado, sea directamente a través de las vinculaciones externas de grupos presentes, o sea a través de la posición estratégica de algún grupo dominante entre el accionariado. En este sentido, las relaciones internas de poder entre los agentes empresariales son muy importantes y aportan casuísticas particulares para cada empresa. Un caso particular es el de la participación directa del sistema bancario, y cada vez más del financiero, sobre el sistema productivo, que conllevará que el tratamiento de la distribución territorial de los centros de decisión deba ser relativizada respecto a los propietarios últimos del capital. En particular desde los años 1980 están adquiriendo creciente protagonismo los fondos de capital riesgo (private equity) que se han convertido en el operador más activo del cambio en el mundo empresarial ${ }^{3}$.

Aun con estas limitaciones, la localización de los centros direccionales aportará diversos tipos de información, entre los cuales destaca aquella vinculada a los atractivos y potencialidades de las economías de urbanización (que podríamos calificar de economías de metropolización) sobre la base de economías de concentración, de aglomeración y de escala que aportan ciertos núcleos urbanos y metropolitanos. En este punto aparecen el sistema financiero y los servicios a las empresas como factores específicos en la capacidad de desarrollo de la actividad directiva hacia la constitución de las grandes empresas (Noyelle, T. y Stanback Jr, T., 1984; Wheeler, J. O., 1987).

\section{Estructura económica y centros de decisión}

Las empresas reciben una parte importante de su consideración y poder social por la capacidad de su volumen de negocios. La importancia de esta magnitud empresarial deriva de que representa una masa de actividad económica directa o indirectamente controlada en sus manos, sea como capacidad de producir, sea porque indica su capacidad de comercializar lo que otros han producido, o también porque muestra su capacidad de movilizar recursos económicos ajenos, dirigiendo sus flujos hacia uno u otro ámbito productivo y, consiguientemente, territorial. En estos dos últimos casos por su capacidad de potenciar o desincentivar con sus inversiones unas $\mathrm{u}$ otras actividades en unos $\mathrm{u}$ otros lugares. Es lo que representa por ejemplo el uso de los depósitos por parte de las empresas de seguros o los fondos de pensiones.

"Entre las diferencias [con el empresario industrial o al clásico banco accionista de referencia de una empresa] se incluyen el interés por una muy veloz revalorización de la inversión, la presión para vender activos y saldar la deuda con la que se ha realizado la compra y una búsqueda de eficiencia que en muchos casos acaba dejando por el camino algunos de los valores tangibles e intangibles que aseguran la vida a largo plazo de las empresas. Dicho de otra manera, en ocasiones, este tipo de inversiones coloca de un lado el interés del accionista (el que vende y el nuevo propietario) frente al resto de sectores con intereses en una empresa determinada: trabajadores, proveedores, responsables políticos...”, y por tanto al territorio, en lo que nos interesa en este texto (Pérez, M., 2007). 


\section{Ciudad y poder}

Al margen del poder político concentrado específicamente en las capitales nacionales, el poder económico, especialmente en los últimos siglos, ha sido el motor de crecimiento de centros urbanos más diversificados por el territorio. En numerosos casos al amparo del poder político, pero en otros muchos exclusivamente sobre la base de la capacidad de reproducción y ampliación de la dinámica empresarial. Así se formó la ciudad industrial y se está formando la ciudad terciaria.

Simplificando, sabemos que los motores iniciales de los procesos de concentración industrial se basaron de forma esencial en la doble dinámica de aprovechar las economías de aglomeración, de concentración y de escala para dar forma a economías de urbanización y localización. En este proceso se iban ampliando las relaciones complementarias entre empresas, al tiempo que se generaba demanda crítica suficiente para mantener empresarialmente esta diversificación. Es conocido que uno de estos factores fue generar un amplio mercado de trabajo de cualificaciones diversificadas que fomentó el crecimiento poblacional sustentado sobre importantes movimientos inmigratorios hacia ellos. A medida que el comercio con el exterior fue ampliándose, adquirieron creciente importancia las economías de posición en relación con otros territorios suministradores o compradores. En la valorización de las economías de posición será de vital importancia la relación con las infraestructuras de transportes y comunicaciones. De ahí, la vinculación entre centros urbanos y metropolitanos con las redes de autopistas, los sistemas de transporte ferroviarios, los puertos y los aeropuertos.

El poder económico que se irá concentrando en estos núcleos se constituirá en un elemento de presión tanto para la funcionalización del territorio interno como para la potenciación de la accesibilidad a través de los sistemas de transporte y comunicación.

La internacionalización del proceso de globalización potenciará las interrelaciones entre ciudades a escala mundial sobre la base de una red de centros urbanos/metropolitanos que articulan un sistema de flujos de información y decisiones, en suma de poder, que tendrán en los entornos metropolitanos los nodos de expansión territorial. En esta red mundial se observaran diversas jerarquías de ciudades. La pugna por pertenecer a circuitos de mayor nivel jerárquico impulsa a la dinamización del crecimiento de las ciudades hacia una formulación metropolitana cada vez más potente como centro de poder y decisión.

Uno de los aspectos fundamentales en esta asunción de poder se concretará en la presencia de centros de decisión empresariales desde los que se tomen decisiones sobre la organización supraterritorial de la producción, en las decisiones de compra o en los flujos de capital.

El proceso de externalización de actividades empresariales se servirá, al tiempo que fortalecerá, de las economías de aglomeración de actividades directas o indirectas ${ }^{4}$ en una realimentación positiva que puede llegar a comportar deseconomías de aglomeración. Ante esta amenaza los gestores públicos del territorio deberán actuar sobre las políticas urbanas para que estas deseconomías no se produzcan o para amortiguarlas.

En síntesis, los centros urbanos establecerán una pugna en términos de relaciones de poder, no sólo para aumentar su poder, sino también para neutralizar los embates de la competencia externa y de las debilidades internas.

\section{Poder metropolitano y poder de capitalidad}

La estructura de poder urbano se concretará en el territorio bajo la forma de jerarquía urbana, cuyo segmento superior será ocupado por los ámbitos metropolitanos. En ellos el poder económico tomará cuerpo mediante la localización de sus centros de decisión y acción, entre los que destacarán las sedes de las grandes empresas.

El poder económico suele verse reforzado cuando se interrelaciona territorialmente con el poder político. La interrelación entre ambas formas de poder crea sinergias multiplicadoras

\footnotetext{
Un conjunto de estas actividades indirectas se referirá a los servicios a las personas empleadas en los centros Direccionales para satisfacer las demandas familiares del cuerpo de ejecutivos y técnicos de alto nivel que ocupan.
} 
Cuadro 1. Distribución por países de la sede de las 500 mayores empresas mundiales (2005)

\begin{tabular}{|c|c|c|c|c|c|c|c|c|c|}
\hline & \multicolumn{4}{|c|}{ Valores absolutos } & \multicolumn{4}{|c|}{ Valores relativos } & \multirow{2}{*}{$\begin{array}{c}\begin{array}{c}\text { Factor } \\
\text { capitalidad }\end{array} \\
\text { \% empresas } \\
\text { en la capital }\end{array}$} \\
\hline País & $\begin{array}{c}N^{\circ} \text { de } \\
\text { empresas }\end{array}$ & $\begin{array}{l}\text { Ingresos } \\
\text { (M \$) }\end{array}$ & Empleados & $\begin{array}{l}\text { Beneficios } \\
\text { (M \$) }\end{array}$ & $\begin{array}{c}\mathrm{N}^{\circ} \text { de } \\
\text { empresas }\end{array}$ & Ingresos & Empleados & Beneficios & \\
\hline Estados Unidos y Canadá & & & & & 36,6 & 37,0 & 36,5 & 39,5 & \\
\hline 1 Estados Unidos & 169 & 6.741 .954 & 17.584 .665 & 455.045 & 33,8 & 35,6 & 34,8 & 38,0 & 4,1 \\
\hline 2 Canadá & 14 & 268.478 & 840.772 & 18.132 & 2,8 & 1,4 & 1,7 & 1,5 & 0 \\
\hline 3 Europa (sin Rusia) & & & & & 35,6 & 40,1 & 34,7 & 38,9 & \\
\hline $4 \overline{\text { Francia }}$ & 38 & 1.614 .947 & 4.895 .755 & 97.709 & 7,6 & 8,5 & 9,7 & 8,1 & 94,7 \\
\hline 5 Gran Bretaña & 38 & 1.555 .327 & 3.152 .688 & 84.788 & 7,6 & 8,2 & 6,2 & 7,1 & 84,6 \\
\hline 6 Alemania & 35 & 1.649 .987 & 4.360 .492 & 67.058 & 7,0 & 8,7 & 8,6 & 5,6 & 2,9 \\
\hline 7 Holanda & 14 & 821.672 & 1.328 .440 & 58.935 & 2,8 & 4,3 & 2,6 & 4,9 & 78,6 \\
\hline 8 Suiza & 12 & 481.396 & 873.714 & 41.304 & 2,4 & 2,5 & 1,7 & 3,4 & 0 \\
\hline 9 Italia & 10 & 427.302 & 894.451 & 33.983 & 2,0 & 2,3 & 1,8 & 2,8 & 50 \\
\hline 10 España & 9 & 263.640 & 663.046 & 30.257 & 1,8 & 1,4 & 1,3 & 2,5 & 77,8 \\
\hline 11 Suecia & 6 & 118.575 & 322.309 & 11.158 & 1,2 & 0,6 & 0,6 & 0,9 & 83,3 \\
\hline 12 Bélgica & 4 & 133.338 & 287.597 & 6.903 & 0,8 & 0,7 & 0,6 & 0,6 & 100 \\
\hline 13 Varios Paises Europeos & 2 & 161.932 & 260.245 & 9.575 & 0,4 & 0,9 & 0,5 & 0,8 & $\left({ }^{*}\right)$ \\
\hline 14 Irlanda & 2 & 92.869 & 121.466 & 1.175 & 0,4 & 0,5 & 0,2 & 0,1 & 100 \\
\hline 15 Noruega & 2 & 88.066 & 58.409 & 7.196 & 0,4 & 0,5 & 0,1 & 0,6 & 50 \\
\hline 16 Finlandia & 2 & 58.871 & 105.538 & 4.336 & 0,4 & 0,3 & 0,2 & 0,4 & 100 \\
\hline 17 Dinamarca & 2 & 57.552 & 86.626 & 5.487 & 0,4 & 0,3 & 0,2 & 0,5 & 100 \\
\hline 18 Luxemburgo & 1 & 40.521 & 96.256 & 4.779 & 0,2 & 0,2 & 0,2 & 0,4 & 100 \\
\hline 19 Austria & 1 & 19.389 & 49.919 & 1.561 & 0,2 & 0,1 & 0,1 & 0,1 & 100 \\
\hline 20 Sudeste Asiático & & & & & 22,8 & 19,1 & 24,2 & 15,3 & \\
\hline $21 \overline{\text { Japón }}$ & 70 & 2.328 .344 & 4.940 .382 & 105.827 & 14,0 & 12,3 & 9,8 & 8,8 & 75,7 \\
\hline 22 China & 20 & 617.448 & 6.172 .798 & 30.838 & 4,0 & 3,3 & 12,2 & 2,6 & 75 \\
\hline 23 Corea & 12 & 402.435 & 402.675 & 22.663 & 2,4 & 2,1 & 0,8 & 1,9 & 91,7 \\
\hline 24 India & 6 & 120.395 & 307.778 & 8.185 & 1,2 & 0,6 & 0,6 & 0,7 & 33,3 \\
\hline 25 Taiwan & 3 & 62.720 & 287.819 & 2.285 & 0,6 & 0,3 & 0,6 & 0,2 & 100 \\
\hline 26 Malasia & 1 & 44.280 & 33.682 & 11.565 & 0,2 & 0,2 & 0,1 & 1,0 & 100 \\
\hline 27 Tailandia & 1 & 23.109 & 7.843 & 2.126 & 0,2 & 0,1 & 0,0 & 0,2 & 100 \\
\hline 28 Singapur & 1 & 15.566 & 99.000 & 141 & 0,2 & 0,1 & 0,2 & 0,0 & 100 \\
\hline 29 Otros países & & & & & 5,0 & 3,8 & 4,5 & 6,3 & \\
\hline 30 Australia & 8 & 174.778 & 388.241 & 21.435 & 1,6 & 0,9 & 0,8 & 1,8 & 0 \\
\hline 31 Rusia & 5 & 157.700 & 1.152 .111 & 31.381 & 1,0 & 0,8 & 2,3 & 2,6 & 80 \\
\hline 32 México & 5 & 146.817 & 371.426 & -2.397 & 1,0 & 0,8 & 0,7 & $-0,2$ & 80 \\
\hline 33 Brasil & 4 & 115.390 & 273.664 & 15.259 & 0,8 & 0,6 & 0,5 & 1,3 & 25 \\
\hline 34 Venezuela & 1 & 85.618 & 48.919 & 4.661 & 0,2 & 0,5 & 0,1 & 0,4 & 100 \\
\hline 35 Arabia Saudi & 1 & 20.865 & 17.000 & 5.109 & 0,2 & 0,1 & 0,0 & 0,4 & 100 \\
\hline 36 Turquía & 1 & 18.084 & 47.801 & 444 & 0,2 & 0,1 & 0,1 & 0,0 & 0 \\
\hline Total mundial & 500 & 18.929 .365 & 50.533 .527 & 1.198 .903 & 100 & 100 & 100 & 100 & 43,4 \\
\hline
\end{tabular}

${ }^{*}{ }^{*}$ Incoporados a la ciudad donde se halla su sede: Bruselas y Londres

Fuente. Elaboración propia sobre datos de Fortune Global 500 (2005).

de poder, las cuales toman forma territorial en las capitales de estado. De ahí que en la cúspide del sistema urbano aparezca el factor capitalidad como un referente de poder territorializado.

La yuxtaposición en un mismo territorio urbano de ambos poderes aparece como la fórmula más fácil de articular un espacio de poder. Pero aun siendo una forma dominante no es universal, con excepciones como Estados Unidos, Canadá, Alemania o Suiza. Por ser excepciones, no impiden que debamos introducir el factor capitalidad como un elemento importante del análisis de los factores de localización de las sedes de las grandes empresas.

Insistamos en que el factor metropolización lo estamos aplicando no a cualquier tipo de empresa, que puede surgir en territorios de muy diversas características, sino a aquellas que aspiran o alcanzan a ser una gran empresa.

\section{Objetivo del análisis}

La adopción de decisiones por las empresas debe responder a criterios que permitan hacer frente a los objetivos o problemas a los que se enfrenta. En esta categoría entran las decisiones relacionadas con la organización de sus actividades y con su localización territorial.

La localización de su sede social o centro direccional (headquarter) se presupone que responde a lógicas vinculadas a sus objetivos, necesidades y planes empresariales, tanto de organización interna como de relación con el entorno económico. 
Mapa 1. Distribución por países de la sede de las 500 mayores empresas

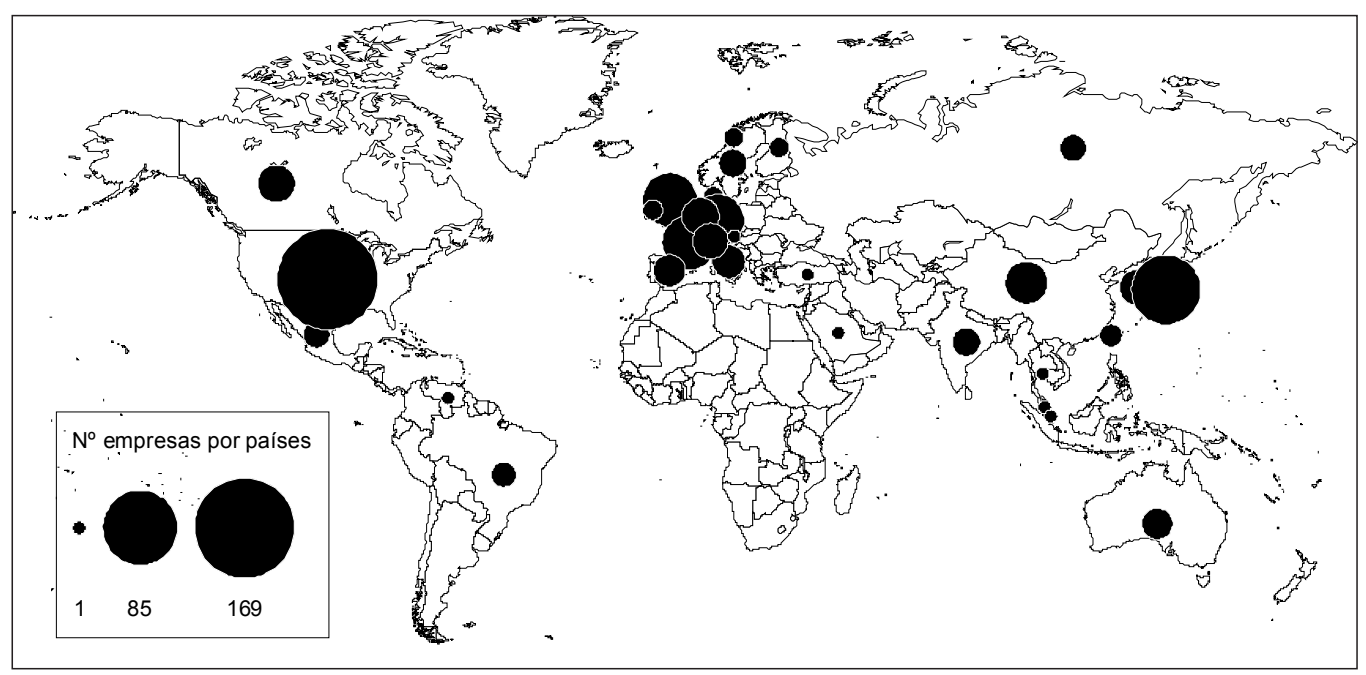

Nuestro interés se centra en este texto en tratar de discernir cuáles pueden ser algunos de estos criterios de decisión que expliquen la localización y distribución de las sedes empresariales de las grandes empresas en relación con las regiones metropolitanas.

Como ya hemos indicado, para alcanzar nuestros objetivos plantearemos el análisis empírico a dos niveles y dos escalas. Al nivel de las centros de decisión de las grandes empresas y al nivel de los centros de decisión subsidiaria de algunas de estas grandes empresas concretados en una nación secundaria (España). Con este contraste la escala mundial de las grandes empresas multinacionales se matizará con lo que ocurre dentro de un territorio secundario en las lógicas de distribución de las sedes primarias y subsidiarias. Ello nos permitirá apreciar las interrelaciones entre ambos tipos de empresas y su vinculación territorial.

Se trata de abstraer si pueden establecerse pautas de comportamiento por parte de las grandes empresas. De ser así, permitiría establecer qué factores intervienen en las decisiones de localización, y cuál es la resultante en el mapa de la distribución de los centros de poder empresarial, con las consecuencias que puede conllevar sobre el conjunto del territorio. De ello debería derivarse un modelo provisional de interpretación en la relación entre localización de sedes y el papel de los ámbitos metropolitanos.

\section{Las sedes de las grandes empresas mundia- les y las metrópolis ${ }^{5}$}

Las sedes de las 500 mayores empresas mundiales se concentran en 32 países (Cuadro 1 y Mapa 1) y en 121 localizaciones (Cuadro 2 y Mapas 2, 3 y 4). Los Estados Unidos por sí solos aportan un tercio del censo total $(33,8 \%)$; Europa, sin contar Rusia, dispone del 35,6\% mientras que Japón se sitúa como segundo país individual más importante con el 14\% dentro del conjunto de territorios del sudeste asiático que representan $22,8 \%$. El último $5 \%$ se reparte por el resto del territorio mundial, con la particularidad de que África no aporta ninguna gran empresa.

El papel de los centros metropolitanos como ámbitos territoriales de localización de las sedes se pone de manifiesto de forma clara dado que representa casi el 87\% de los 121 ámbitos de concentración a escala mundial. Su importancia es todavía mayor por cuanto se ubican en ellas casi el $97 \%$ de empresas (483). Solamente un pequeño porcentaje de empresas $(17,4 \%)$ no ha necesitado

5 La base empírica de esta parte del trabajo la constituye la información procedente de Fortune, 2006. 
Cuadro 2. Distribución por ámbitos territoriales de las 500 mayores empresas mundiales (2005)

\begin{tabular}{|l|r|r|r|r|r|}
\cline { 2 - 6 } \multicolumn{1}{c|}{} & $\begin{array}{c}\mathbf{N}^{\circ} \text { ámbitos } \\
\text { territoriales } \\
\text { con EMN }\end{array}$ & $\begin{array}{c}\mathbf{N}^{\circ} \text { de } \\
\text { empresas }\end{array}$ & $\begin{array}{c}\text { Ingresos } \\
\mathbf{( M \$ )}\end{array}$ & $\begin{array}{r}\text { Empleados } \\
\text { Total en Regiones Metropolitanas }\end{array}$ & $\begin{array}{c}\text { Beneficios } \\
\text { (M\$) }\end{array}$ \\
\hline Total en ámbitos no metropolitanos & 105 & 483 & 17.912 .456 & 47.162 .482 & 1.184 .049 \\
\hline Total & 121 & 17 & 1.016 .909 & 3.371 .045 & 14.854 \\
\hline
\end{tabular}

\begin{tabular}{l}
\hline Media por empresa \\
\begin{tabular}{|l|r|r|r|r|r|}
\hline \multicolumn{3}{|l|}{} & 37.859 & 101.067 & 2.398 \\
\hline Total en Regiones Metropolitanas & 86,8 & 96,6 & 94,6 & 93,3 & 98,8 \\
Total en ámbitos no metropolitanos & 13,2 & 3,4 & 5,4 & 6,7 & 1,2 \\
\hline Total & 100 & 100 & 100 & 100 & 100 \\
\hline
\end{tabular}
\end{tabular}

Fuente. Elaboración propia sobre datos de Fortune Global 500 (2005) y ONU

Mapa 2. Distribución por ciudades de las mayores empresas en el Norte de América

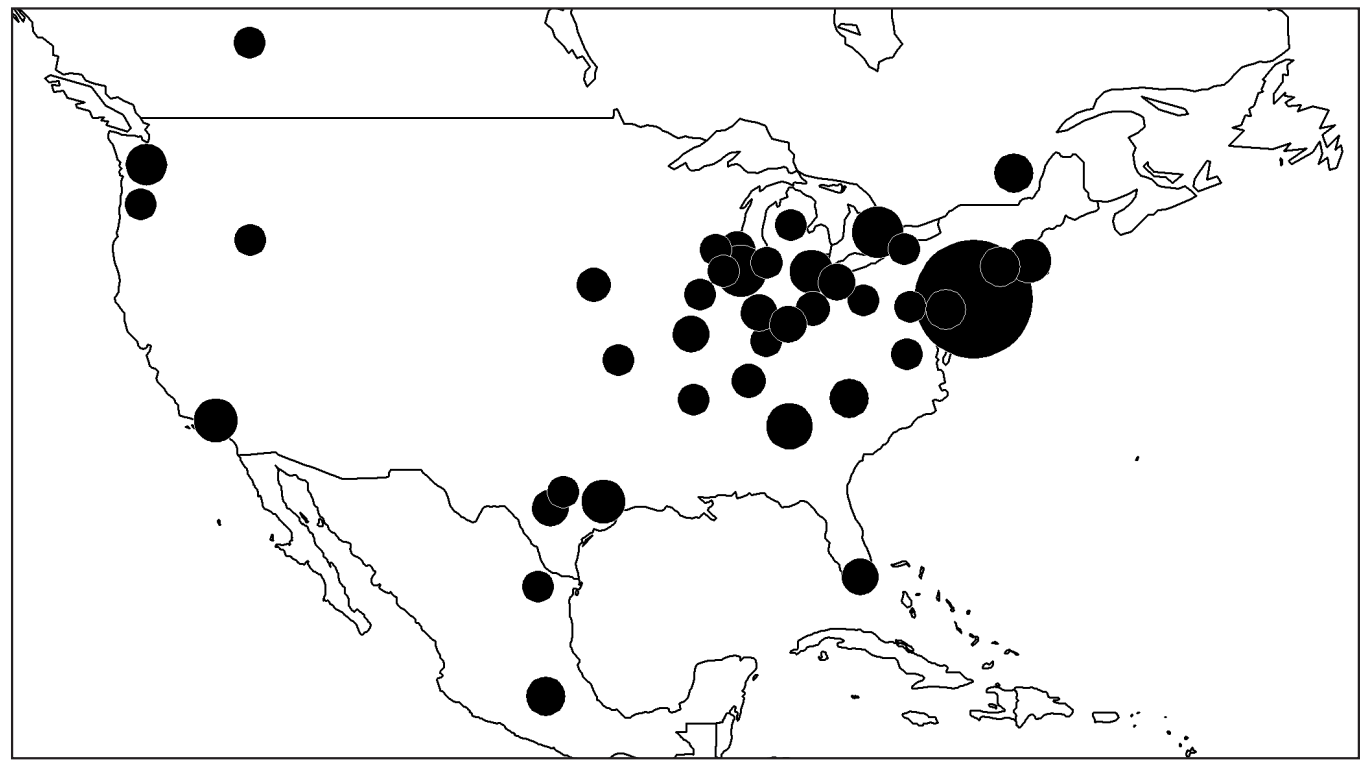

Fuente. Elaboración propia sobre datos de Fortune Global 500 (2005).

o no ha sido capaz de generar una dinámica de metropolización ${ }^{6}$.

De éstas, un parte importante corresponde a empresas de tipo industrial fuertemente enraizadas con la localización de su centro productivo original (Dow Chemical, Whirlpool, Nestlé, Caterpillar, Deere, Volkswagen, Michelin, Novartis o Roche Group). Otras tres relacionadas con las fuentes de energía (Statoil, Surgutneftegas y Scottish \& Southern Energy). Alguna, como siempre, representan excepciones que no llegan a rompen la regla general de metropolización, máxime si tenemos en cuenta que se encuentran en países con una fuerte integración territorial interna (Bertelsmann, Tyson Foods, Wal-Mart Stores, Assicurazioni Generali y Vodafone). A excepción de Statoil todas las demás se sitúan
Este bloque dominante de empresas se ha ido configurando a través de un proceso histórico que arranca de principios del siglo XX cuando se establecieron las condiciones para la producción masiva. Esta masificación fue la que posibilitó el crecimiento de magnitud de las empresas sobre la base de extender la producción hacia la escala mundial, constituyéndose en empresas multinacionales (EMN). Fueron predominantemente

en Europa y Estados Unidos, con una importante tradición a sus espaldas, lo que no se da en las nuevas empresas creadas en los últimos años en los países emergentes. 
Mapa 3. Distribución por ciudades de las mayores empresas en Europa

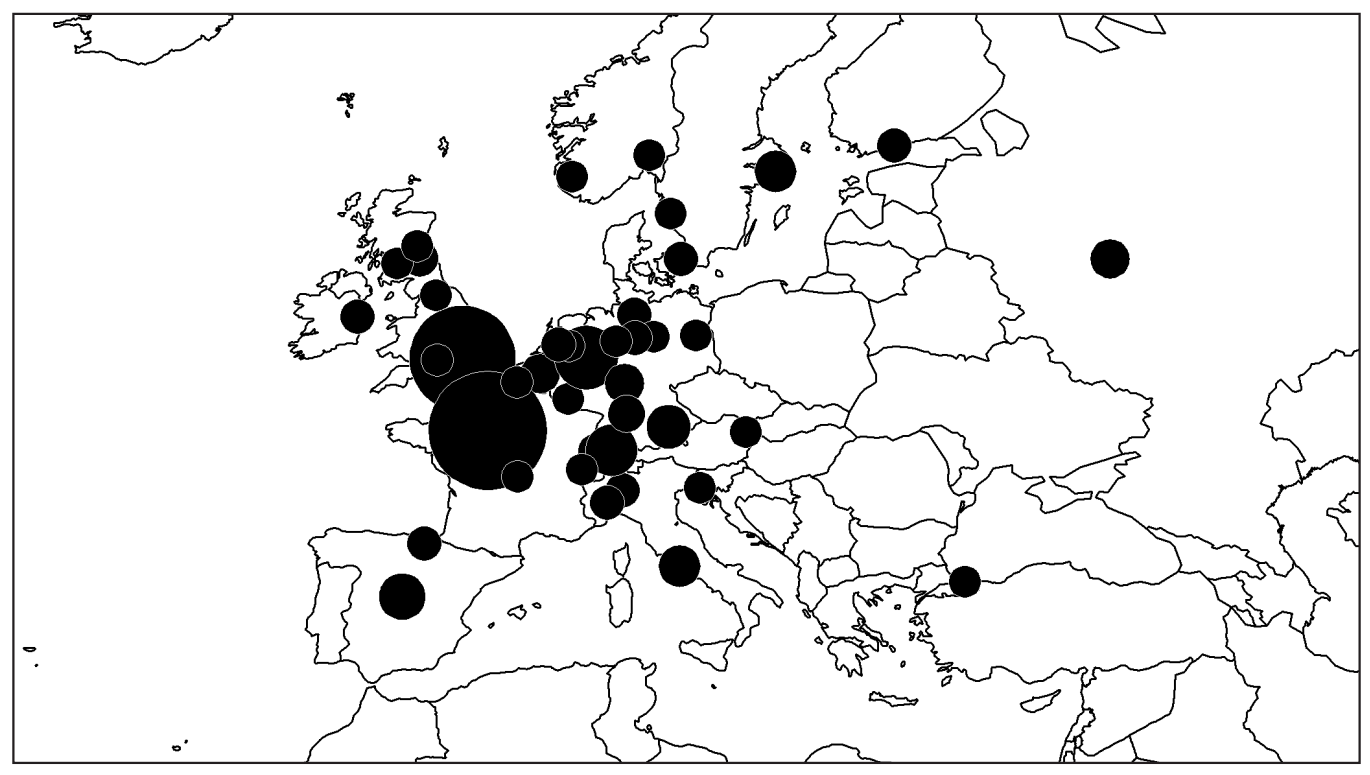

Fuente. Elaboración propia sobre datos de Fortune Global 500 (2005).

Mapa 4. Distribución por ciudades de las mayores empresas en el Sudeste Asiático

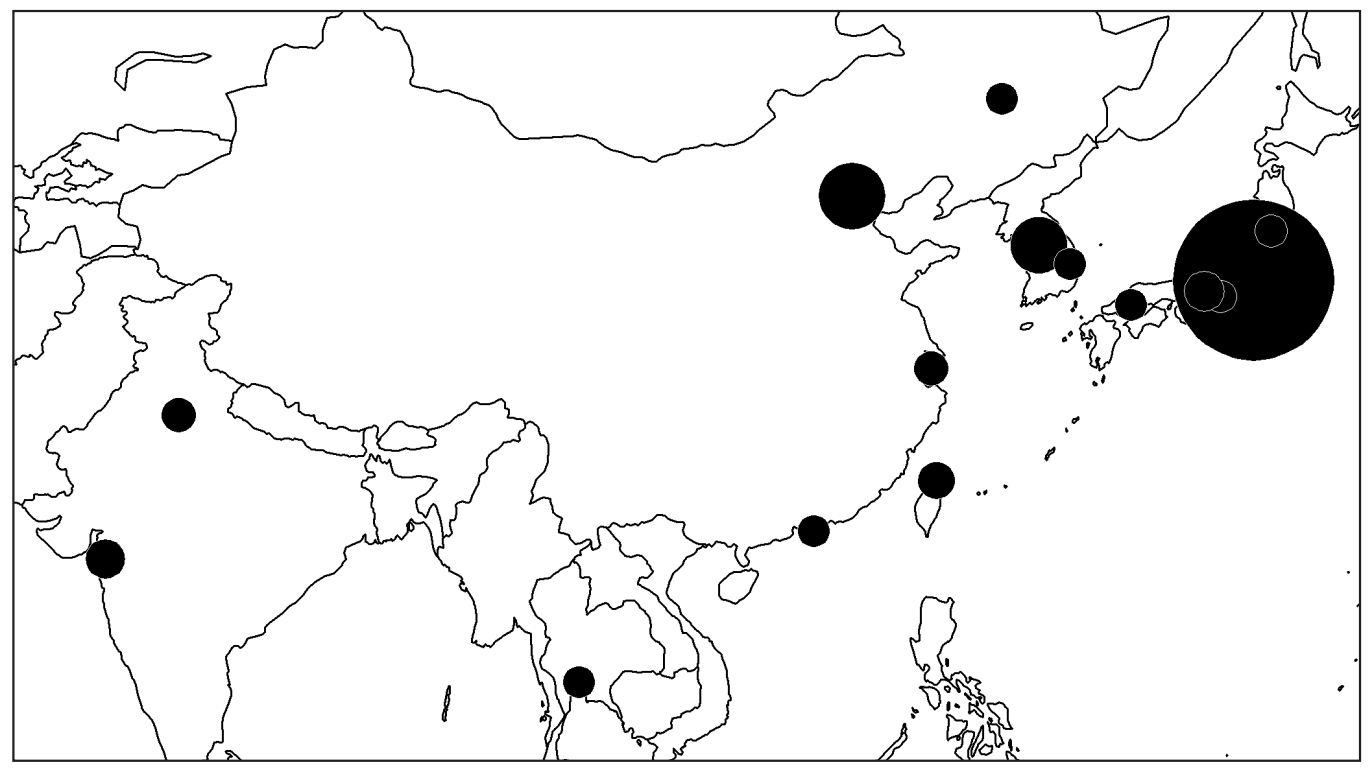

Fuente. Elaboración propia sobre datos de Fortune Global 500 (2005). 
Cuadro 3. Las 500 mayores empresas mundiales por actividad económica (2005)

\begin{tabular}{|c|c|c|c|c|c|c|c|c|c|c|c|}
\hline & & Valore & s absolutos & & & Valores & relativo & & & & \\
\hline Actividad económica & $\begin{array}{c}\mathbf{N}^{\circ} \text { de } \\
\text { empres } \\
\text { as }\end{array}$ & $\begin{array}{l}\text { Ingresos } \\
\text { (M \$) }\end{array}$ & Empleados & $\begin{array}{l}\text { Beneficios } \\
\text { (M \$) }\end{array}$ & $\begin{array}{c}N^{\circ} \text { de } \\
\text { empre } \\
\text { sas }\end{array}$ & $\begin{array}{c}\text { Ingres } \\
\text { os }\end{array}$ & $\begin{array}{c}\text { Emple } \\
\text { ados }\end{array}$ & $\begin{array}{c}\text { Benefi } \\
\text { cio }\end{array}$ & $\begin{array}{c}\text { Beneficio } \\
\text { por } \\
\text { empresa } \\
\text { (M \$) }\end{array}$ & $\begin{array}{c}\text { Beneficio } \\
\text { sobre } \\
\text { Ingresos } \\
(\%)\end{array}$ & $\begin{array}{l}\text { Beneficio } \\
\text { por } \\
\text { empleado } \\
\text { (miles \$) }\end{array}$ \\
\hline Industr & 226 & 9.199 .098 & 22.939 .942 & 612.469 & 45,2 & 48,6 & 45,4 & 51,09 & $2.710,0$ & $\overline{0,7}$ & 26,7 \\
\hline Construcción e ingeniería & 14 & 238.971 & 1.384 .746 & 9.829 & 2,8 & 1,262 & 2,74 & 0,82 & 702,1 & 0,4 & 7,1 \\
\hline Servicios & 260 & 9.491 .296 & 26.208 .839 & 576.605 & 52 & 50,14 & 51,86 & 48,09 & $2.217,7$ & 0,6 & 22,0 \\
\hline
\end{tabular}

Fuente. Elaboración propia sobre datos de Fortune Global 500 (2005).

Cuadro 4. Aglomeraciones con mayor concentración de las 500 sedes empresariales y efecto capitalidad (2005)

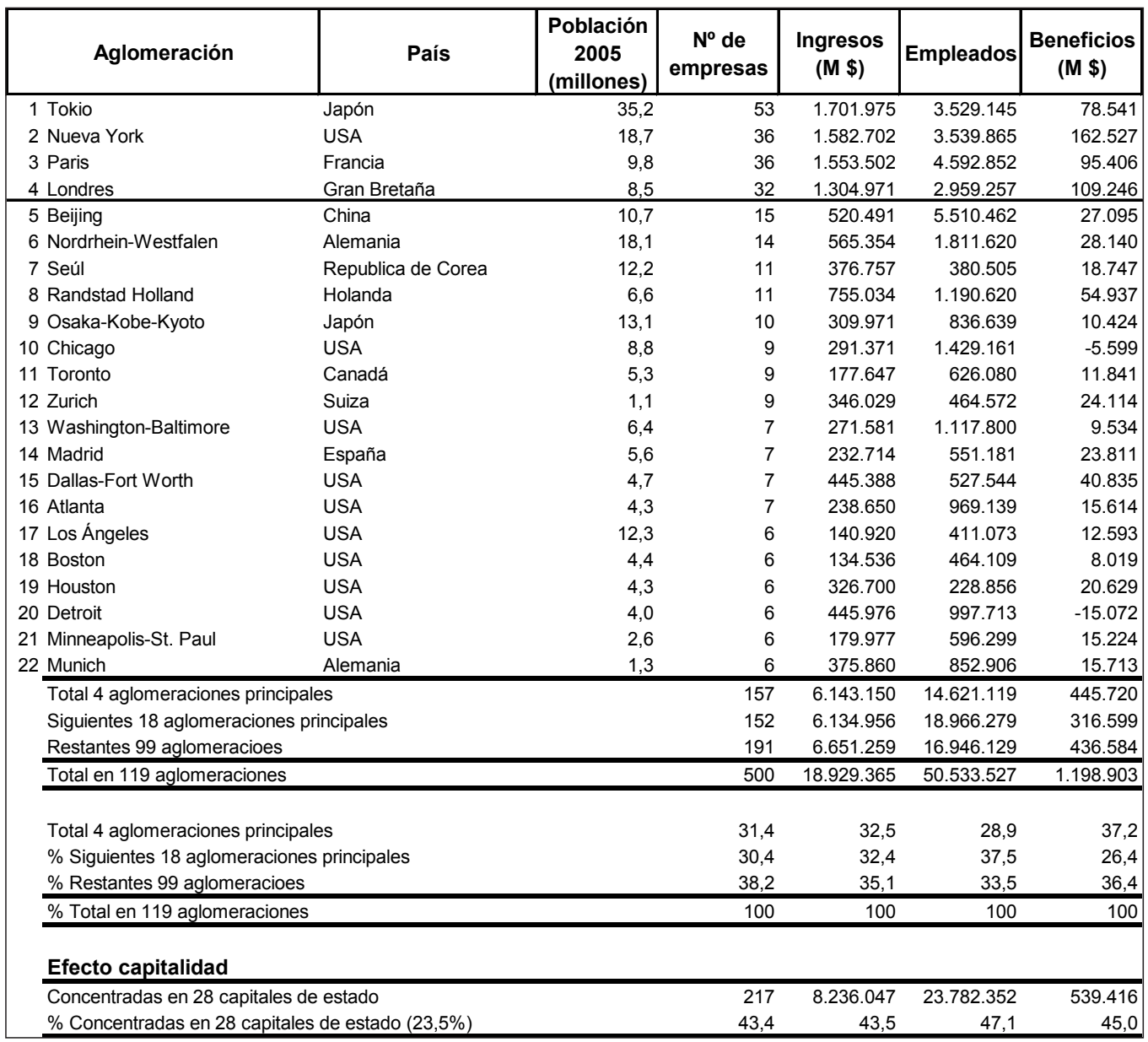

empresas de base industrial: automóvil, química, electricidad y electrónica o extracción y refino de petróleo. Siguiendo la evolución técnica y la terciarización se han ido incorporando a este selecto bloque nuevas empresas más diversificadas, con creciente presencia de los servicios. En la situación actual la industria aporta el 45\% de las grandes empresas frente al 52\% de los servicios, que se completa con un 3\% de empresas de construcción e ingeniería (Cuadro 3). 
En este proceso el hecho metropolitano aparece como causa y como efecto. Como efecto sobre la metropolización en la medida en que la localización inicial de ciertas empresas constituyó uno de los motores del crecimiento de los núcleos en los que se habían localizado, generando economías de urbanización a partir de la sucesión de interrelaciones entre economías de aglomeración, de concentración y de escala. Por tanto, una gran parte del crecimiento metropolitano de las ciudades que no son capital de Estado, responden al efecto de las implantaciones iniciales, y su posterior expansión, entre las que encontramos a muchas de las todavía dominantes. Sobre la base de este proceso las condiciones de urbanización que se iban potenciando han servido como causa de nacimiento o implantación de nuevas empresas, que a su vez han alcanzado el liderazgo mundial que este grupo refleja. La expansión de los servicios, y muy especialmente la banca, han aprovechado las economías de urbanización en beneficio propio como base de su potenciación. Este doble proceso es el que ha configurado los 105 ámbitos territoriales metropolitanos que detectamos.

Ahora bien, si la metrópolis encarna el lugar idóneo de localización de las sedes empresariales, no lo es el proceso inverso. No todo entorno metropolitano, o mejor sería decir aglomeración urbana, presenta las condiciones idóneas para la dinamización empresarial; significa que ni el contexto metropolitano concreto, ni el entorno externo de país habrán ofrecido las ventajas de localización que dan lugar a este tipo de empresas. En este sentido verificamos que sobre un conjunto estadístico de 507 aglomeraciones urbanas de más de 1 millón de habitantes y de capitales de los Estados, aun cuando no alcancen esta dimensión, sólo 105 aparecen como metrópolis idóneas. Debemos matizar que al limitar a 500 las empresas de análisis necesariamente deben quedar matemáticamente áreas sin cubrir que se incorporarían al ranking si, por ejemplo, analizásemos las 2000 mayores empresas. Ello no obsta para que quede planteada una línea de análisis que profundizase en las condiciones de competitividad diferencial ente unas y otras metrópolis para ser capaces de generar, $\mathrm{o}$ no, el nacimiento de grandes empresas en su seno.

Insistamos en que estamos hablando de empresas que se han creado y que han alcanzado la dimensión de gran empresa mundial. Por tanto, lo que el hecho metropolitano aporta es la capacidad del entorno territorial para crear y activar fuertes dinámicas de crecimiento empresarial. En este momento no estamos situados en el ámbito de la capacidad de atracción de un territorio sobre inversiones externas, sino de dinamizar empresas internas. La capacidad de atracción será el motivo de la siguiente parte del análisis centrado en territorios que denominaremos "secundarios".

En resumen, como causa y/o como efecto circular, las condiciones metropolitanas aparecen con toda claridad como condición necesaria para el desarrollo de grandes corporaciones.

En concreto, las regiones metropolitanas de Tokio (53), Nueva York (36), París (36) y Londres (33), son los cuatro centros principales de poder empresarial (Cuadro 4). Solamente desde estos cuatro centros se controla casi un tercio de la actividad de las grandes corporaciones. Las 18 siguientes regiones metropolitanas, con más de 5 empresas por aglomeración, representan aproximadamente otro tercio. Mientras que el último tercio se reparte entre las restantes 99 localizaciones. En volumen representa que de los 50,5 millones de empleados que trabajan para estas empresas, casi 15 millones son controlados desde cuatro ciudades; así como el 32,7\% de los ingresos (6.192.713 M\$) y el 37\% de los benefi$\operatorname{cios}(450.000 \mathrm{M} \$)$.

El aparente menor poder de concentración de Nueva York ${ }^{7}$ respecto a Tokio queda compensado en términos de control por cuanto los ingresos se sitúan ligeramente por debajo, mientras que el control sobre empleados, y muy especialmente de beneficios, más que duplican a los obtenidos por Tokio.

\section{El factor capitalidad}

El factor metrópolis se refuerza en general a través del factor capitalidad. En efecto, de los 32 países representados en el ranking de las 500 mayores empresas solamente en 3 (9\%) la capi-

Algunos trabajos apuntan en la dirección de que en Estados Unidos se produce un cierto desplazamiento de sedes hacia territorios menos metropolitanos (Quark, A. A., 2007). 
tal del Estado no aporta ninguna gran empresa (Canadá, Suiza y Australia) y en otros 3 (Estados Unidos, Alemania y Brasil) la capital tiene una concentración minoritaria. En contrapartida, en 24 países $(75 \%)$ la capital concentra la mayoría de sedes, en los cuales $12(38 \%)$ solamente la capital concentra empresas.

Observemos que en los casos en que no se da el efecto capitalidad sus procesos históricos han seguido pautas muy particulares. En ellos la ubicación de la capital ha obedecido a razones particulares desvinculadas del papel económico y mucho más vinculada a razones de oportunidad política, como puede ser Brasilia o Berlín. En Estados Unidos, y también en Alemania, la dispersión territorial puede ser explicada, además de por su estructura federal, como en Suiza, por el proceso de expansión económica a lo largo del siglo XX.

En su conjunto, como hemos teorizado en la introducción de este artículo, las cifras analizadas a escala mundial reflejan claramente que el poder se concentra en unas pocas empresas y desde unos pocos territorios.

La imagen que se desprende del análisis a esta escala mundial, y para el comparativamente reducido número de empresas, conviene completarla con una visión a otra escala, la de país, en la que podrá visualizarse un más detallado papel de las metrópolis en la organización del poder de las grandes empresas. Para ello podemos plantear este cambio de escala aplicado a los que denominaremos naciones secundarias, entendidas como aquellas que, aun aportando empresas de tamaño mundial, son importantes receptores de inversión extranjera directa en forma de empresas subsidiarias, al tiempo que disponen de empresas de tamaño grande en relación con el sistema económico interno (local).

\section{Las grandes empresas en naciones secundarias}

Nos situamos así en un segundo nivel territorial desde la perspectiva empresarial, aquel en el que sobre un territorio confluyen al mismo tiempo creación de grandes empresas, aunque sea a un nivel secundario, y localización de empresas subsidiarias de los grandes grupos multinacionales como los representados en el apartado anterior. A esta escala territorial volveremos a preguntarnos por el papel de los contextos metropolitanos, ahora en su doble capacidad de ser entornos de creación de grandes empresas y de ser centros de atracción de subsidiarias de grandes empresas. Efectuaremos un estudio de caso a partir de España.

\section{Los centros metropolitanos en España}

En el sistema urbano español se distinguen 2 grandes centros metropolitanos con más de 5 millones de habitantes, Madrid y Barcelona, y 5 formados sobre la base de núcleos centrales de más de medio millón de habitantes (Vizcaya-Guipúz$\mathrm{coa}^{8}$, Valencia, Sevilla, Zaragoza y Málaga).

Tomando como referencia las 1000 mayores empresas jurídicas que actúan en territorio español vemos (Cuadro 5 y Mapa 5) como Madrid concentra el $45 \%$ de empresas y Barcelona el $25 \%$. En total estos dos núcleos aglutinan casi el $70 \%$ de las grandes empresas. Los otros 5 entornos considerados suman entre ellos un total del $12 \%$, que sumados a los anteriores aglutina al $81 \%$ de las sedes de las grandes empresas, quedando un residual $19 \%$ a repartir por el resto del territorio español.

Medida la correlación entre dimensión del volumen de población y la localización de empresas, alcanza un elevado coeficiente del 0,91. Lo que valida la hipótesis que se mantiene sobre el papel principal de las economías de urbanización sobre la concentración de poder empresarial.

En el Mapa 5 se visualiza una bipolarización del agrupamiento de centros de decisión en aquellas ciudades-metrópolis que polarizan a su vez el territorio global. Como hemos señalado, esta bipolarización tiene un polo dominante en Madrid y uno secundario en Barcelona.

Madrid asume el papel de capital política del Estado y el de capital económica. Con el $13,6 \%$ de población localiza el $44,5 \%$ de las sedes

Dada la configuración geográfica y urbana ha parecido oportuno considerar el conjunto de territorios de Vizcaya-Guipúzcoa, con sus capitales Bilbao y San Sebastián, como formando un único entorno metropolitano desde la perspectiva de las articulaciones empresariales. 
Cuadro 5. Distribución por ámbitos territoriales de las grandes empresas en España (2004)

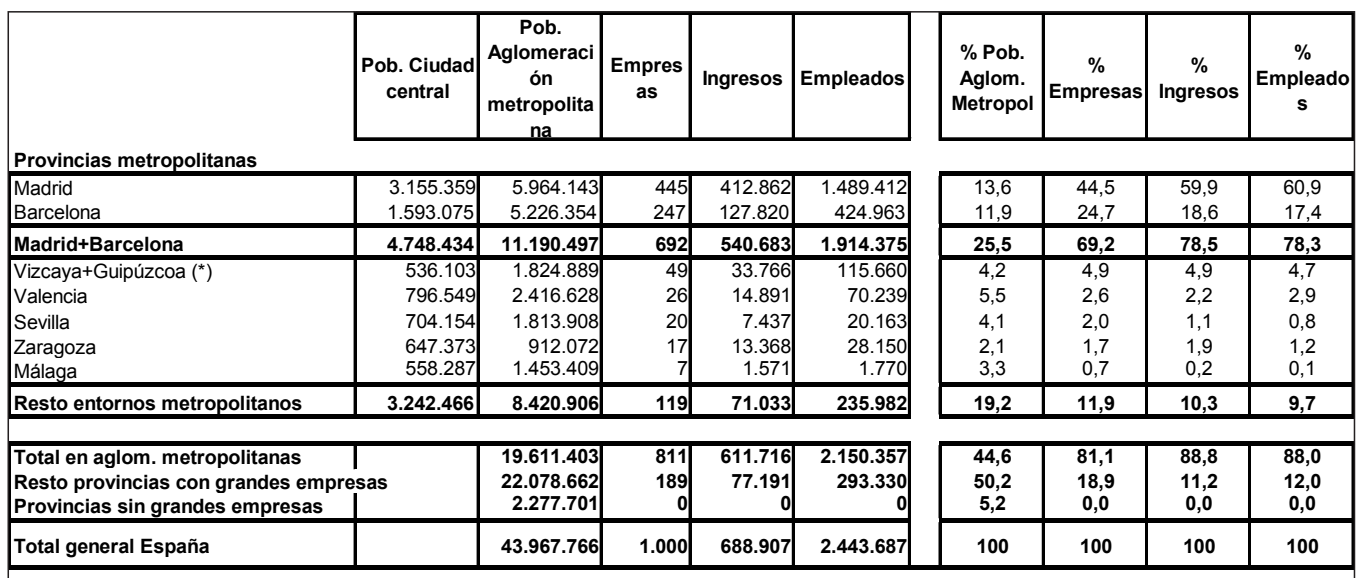

$\left(^{*}\right)$ Considerada en su conjunto como una zona metropolitana

Fuente. Elaboración propia sobre datos de Fomento de la Producción y fuentes diversas

Mapa 5. Sedes de las grandes empresas en España por municipios (2004)

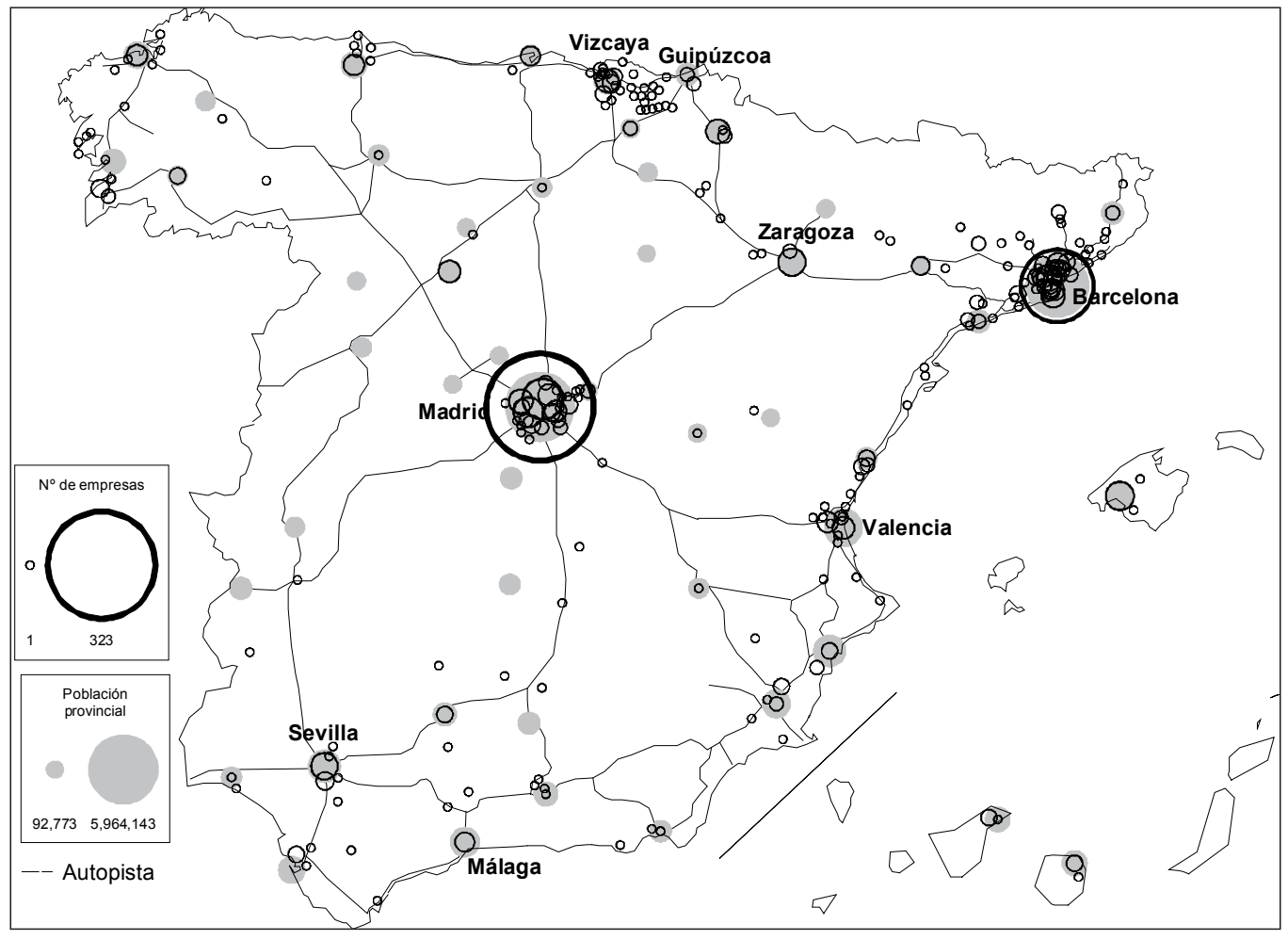

Fuente. Elaboración propia sobre datos de Fomento de la Producción y fuentes diversas 
Joan-Eugeni Sánchez

Cuadro 6. Localización de las grandes empresas en España según sector de actividad y por Implantación Multinacional Directa (2004)

\begin{tabular}{|c|c|c|c|c|c|c|c|c|c|c|}
\hline Ámbito territorial & $\underset{\begin{array}{c}\text { Energía y } \\
\text { agua }\end{array}}{ }$ & $\begin{array}{c}\text { Miner.no } \\
\text { energ. } \\
\text { Quimica }\end{array}$ & $\begin{array}{c}\text { Ind. transf. } \\
\text { de } \\
\text { metales }\end{array}$ & $\begin{array}{c}\text { Otras ind. } \\
\text { manufactu } \\
r\end{array}$ & $\begin{array}{c}\text { Construcc } \\
\text { ión }\end{array}$ & $\begin{array}{l}\text { Comercio } \\
\text { hosteleria }\end{array}$ & $\begin{array}{c}\text { Transport } \\
\text { e y } \\
\text { comunic }\end{array}$ & \begin{tabular}{|c|} 
Finanzas \\
Seguros \\
Serv. \\
emp.
\end{tabular} & $\begin{array}{c}\text { Otros } \\
\text { servicios }\end{array}$ & Total \\
\hline Madrid & 13 & 48 & 45 & 39 & 22 & 114 & 40 & 111 & 18 & 450 \\
\hline Barcelona & 4 & 45 & 36 & 50 & 8 & 50 & 10 & 39 & 5 & 247 \\
\hline Total Madrid+Barcelona & 17 & 93 & 81 & 89 & 30 & 164 & 50 & 150 & 23 & 697 \\
\hline Bilbao-San Sebastian & 2 & 6 & 16 & 7 & & 6 & 5 & 7 & & 49 \\
\hline Valencia & & 3 & 3 & 5 & 2 & 9 & 1 & 3 & & 26 \\
\hline Sevilla & & 3 & & 6 & 1 & 7 & & 3 & & 20 \\
\hline Zaragoza & & 1 & 4 & 1. & & 8 & & 3 & & 17 \\
\hline Málaga & & & 1 & 2 & 2 & 1 & & 1 & & 7 \\
\hline Total resto metropolitano & $\overline{2}$ & $\overline{13}$ & 24 & 21 & 5 & 31 & 6 & 17 & 0 & $\overline{119}$ \\
\hline Total metropolitano & 19 & 106 & 105 & 110 & 35 & 195 & 56 & 167 & 23 & 816 \\
\hline Total no Metropolitano & 5 & 23 & 24 & 53 & 7 & 49 & 12 & 10 & 1 & 184 \\
\hline Total general & 24 & 129 & 129 & 163 & 42 & 244 & 68 & 177 & 24 & 1000 \\
\hline \multicolumn{11}{|l|}{ Distribución relativa } \\
\hline Madrid & 54,2 & 37,2 & 34,9 & 23,9 & 52,4 & 46,7 & 58,8 & 62,7 & 75,0 & 45,0 \\
\hline Barcelona & 16,7 & 34,9 & 27,9 & 30,7 & 19,0 & 20,5 & 14,7 & 22,0 & 20,8 & 24,7 \\
\hline Total Madrid+Barcelona & 70,8 & 72,1 & 62,8 & 54,6 & 71,4 & 67,2 & 73,5 & 84,7 & 95,8 & 69,7 \\
\hline Bilbao-San Sebastian & 8,3 & 4,7 & $\overline{12,4}$ & 4,3 & & 2,5 & 7,4 & 4,0 & & 4,9 \\
\hline Valencia & & 2,3 & 2,3 & 3,1 & 4,8 & 3,7 & 1,5 & 1,7 & & 2,6 \\
\hline Sevilla & & 2,3 & & 3,7 & 2,4 & 2,9 & & 1,7 & & 2,0 \\
\hline Zaragoza & & 0,8 & 3,1 & 0,6 & & 3,3 & & 1,7 & & 1,7 \\
\hline Málaga & & & 0,8 & 1,2 & 4,8 & 0,4 & & 0,6 & & 0,7 \\
\hline Total resto metropolitano & 8,3 & 10,1 & 18,6 & 12,9 & 11,9 & 12,7 & 8,8 & 9,6 & 0,0 & 11,9 \\
\hline Total metropolitano & 79,2 & 82,2 & 81,4 & 67,5 & 83,3 & 79,9 & 82,4 & 94,4 & 95,8 & 81,6 \\
\hline Total no Metropolitano & 20,8 & 17,8 & 18,6 & 32,5 & 16,7 & 20,1 & 17,6 & 5,6 & 4,2 & 18,4 \\
\hline Total general & 100 & 100 & 100 & 100 & 100 & 100 & 100 & 100 & 100 & 100 \\
\hline
\end{tabular}

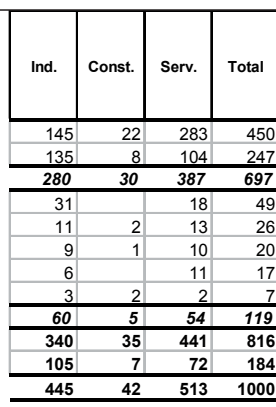

IMPLANTACIÓN MULTINACIONAL DIRECTA

\begin{tabular}{|c|c|c|c|c|c|c|c|c|c|c|}
\hline Madrid & 3 & 25 & 22 & 8 & 1 & 74 & 12 & 36 & 2 & 183 \\
\hline Barcelona & & 21 & 19 & 11 & 1 & 19 & 2 & 8 & & 81 \\
\hline Total Madrid+Barcelona & 3 & 46 & 41 & 19 & 2 & 93 & 14 & 44 & 2 & 264 \\
\hline Bilbao-San Sebastian & & 1 & 1 & 1 & & 1 & 1 & & & 5 \\
\hline Valencia & & & 3 & & & & & & & 3 \\
\hline Sevilla & & & & 1 & & & & 1 & & 2 \\
\hline Zaragoza & & & 2 & & & 1 & & & & 3 \\
\hline \multicolumn{11}{|l|}{ Málaga } \\
\hline Total resto metropolitano & 0 & 1 & 6 & 2 & 0 & 2 & 1 & 1 & 0 & 13 \\
\hline Total metropolitano & 3 & 47 & 47 & 21 & 2 & 95 & 15 & 45 & 2 & 277 \\
\hline Total no Metropolitano & 1 & 6 & $\underline{9}$ & 2 & & 2 & 1 & & & 21 \\
\hline Total general & 4 & 53 & 56 & 23 & 2 & 97 & 16 & 45 & 2 & 298 \\
\hline \multicolumn{11}{|l|}{ Distribución relativa } \\
\hline Madrid & 75,0 & 47,2 & 39,3 & 34,8 & 50,0 & 76,3 & 75,0 & 80,0 & 100,0 & 61,4 \\
\hline Barcelona & & 39,6 & 33,9 & 47,8 & 50,0 & 19,6 & 12,5 & 17,8 & & 27,2 \\
\hline Total Madrid+Barcelona & 75,0 & 86,8 & 73,2 & 82,6 & 100,0 & 95,9 & 87,5 & 97,8 & 100,0 & 88,6 \\
\hline Bilbao-San Sebastian & & 1,9 & 1,8 & 4,3 & & 1,0 & 6,3 & & & 1,7 \\
\hline Valencia & & & 5,4 & & & & & & & 1,0 \\
\hline Sevilla & & & & 4,3 & & & & 2,2 & & 0,7 \\
\hline Zaragoza & & & 3,6 & & & 1,0 & & & & 1,0 \\
\hline Málaga & & & & & & & & & & 0,0 \\
\hline Total resto metropolitano & 0,0 & 1,9 & 10,7 & 8,7 & 0,0 & 2,1 & 6,3 & 2,2 & 0,0 & 4,4 \\
\hline Total metropolitano & 75,0 & 88,7 & 83,9 & 91,3 & 100,0 & 97,9 & 93,8 & 100,0 & 100,0 & 93,0 \\
\hline Total no Metropolitano & 25,0 & 11,3 & 16,1 & 8,7 & 0,0 & 2,1 & 6,3 & 0,0 & 0,0 & 7,0 \\
\hline Total general & 100 & 100 & 100 & 100 & 100 & 100 & 100 & 100 & 100 & 100 \\
\hline
\end{tabular}

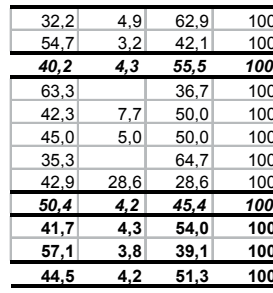

Fuente. Elaboración propia sobre datos de Fomento de la Producción y fuentes diversas

(445 empresas). Su papel dominante se pone ampliamente de manifiesto al controlar más de la mitad de los ingresos $(59,9 \%)$ y de los empleos $(60,9 \%)$. En este sentido recordar que Madrid aparecía situada en la posición 14 a escala mundial (Cuadro 4). Por su parte Barcelona, asume un papel de capital económica secundaria alejada del poder político, ya que con el $11,9 \%$ de población concentra el $24,7 \%$ de empresas pero dispone de un poder muy inferior al de la capital, por cuanto reduce su control al 18,6\% de los ingresos y el $17,4 \%$ de los empleos.
El restante conjunto de empresas implanta su sede en localidades pequeñas, con preponderancia de las capitales de provincia, en una distribución aparentemente aleatoria sobre el territorio global. No obstante, la dispersión por el territorio aparece relacionada con la red de autopistas como elemento articulador del espacio económico de las grandes empresas. Sobre esta estructura los factores sectoriales nos ayudarán a interpretar esta aparente aleatoriedad. 


\section{Características generales de los factores de localización en función del tipo de activi- dad}

En efecto, el tipo de actividad que desarrolla la empresa (Cuadro 6) aparece como un factor explicativo en la localización diferencial sobre el territorio español que se puede sintetizar en los siguientes puntos:

Las actividades industriales presentan mayor vinculación con factores productivos territoriales y con el asentamiento de su núcleo productivo principal. En este último caso se hace patente la tradición industrial de los distintos territorios.

- Por su parte, las actividades terciarias, al estar en general más vinculadas a la oferta de productos o a servicios para el mercado, y por tanto más desvinculadas del hecho productivo territorializado, manifiestan una tendencia a asentarse en grandes núcleos o capitales de provincia desde los que mejor articular las redes de distribución. Estas localizaciones les ofrecen las condiciones mínimas en cuanto a economías de urbanización de donde nutrirse de servicios complementarios pero bien interconectadas como centros de decisión y de poder superior. $\mathrm{Su}$ ubicación diversificada busca aprovechar de forma particular las economías de posición que les permitan entrar en relación con los mercados regionales

En cuanto al sector de las grandes compañías de construcción, obras públicas e inmobiliarias, que se nutren en gran medida de los presupuestos públicos para infraestructuras y obra publica o en grandes proyectos inmobiliarios, buscarán la cercanía con el poder político (como inversor principal) o con los grandes núcleos de población. De ahí la polarización asimétrica entre la capital del Estado, como gran núcleo de concentración $(52,4 \%)$ y, a gran distancia, el segundo polo metropolitano (19\%), mientras un escaso $27 \%$ se distribuye entre algunas capitales de provincia.

\section{El poder metropolitano}

Efectuemos una aproximación sintética en las interrelaciones entre poder económico y poder político para el caso español.

Madrid y el poder de capitalidad. La capital del Estado incorpora centros direccionales de todo tipo de actividades, sobre la base de factores de localización estratégica relacionados con los centros de poder. Es un territorio especialmente atractivo para aquellas actividades que en sí mismas no requieren ni vinculación territorial ni actividad productiva material.

El máximo papel concentrador de la capital se sitúa en el ámbito de las actividades terciarias. Por un lado en relación con la administración pública y a sus infraestructuras de servicios (ferrocarril, correo, comunicaciones). Por otro, aquellas actividades terciarias de servicios a las empresas y a la Administración, de las que se sirven en gran medida las empresas multinacionales, también muestran una clara tendencia dominante a situarse en el centro de poder político-económico territorial.

Las actividades de servicios dirigidas al mercado interior español, en gran parte constituidas por empresas multinacionales que no producen en España, optan asimismo por situar su centro de decisión en el Centro organizador del territorio a escala española que representa la capital del Estado.

Pero la capital no es sólo un centro de servicios sino que constituye un gran polo de actividad productiva industrial. Su proceso de crecimiento más reciente le ha permitido dirigirse hacia sectores con mayor componente tecnológica o con peso institucional.

Barcelona, metrópolis sin poder político. El segundo polo metropolitano localizado en Barcelona, y que concentra casi el 25\% de las empresas, muestra otras pautas en los criterios sectoriales de localización. Este polo se fraguó sobre la base de la industria y el comercio en la tradición anterior a la 
revolución industrial y se consolidó con ésta.

Por ello la tradición industrial y comercial muestra su presencia como factor de localización. Aun así, solamente en algunas actividades industriales es capaz de superar al polo central. Industria textil, agroalimentaria o química son algunas de las actividades predominantes en este segundo polo.

También están presentes actividades terciarias aunque en un grado inferior al del polo dominante y a su vez con menor dinámica en su proyección de futuro.

El País Vasco con problemas políticos. El tercer polo, de muy inferior intensidad (6\% de empresas), está formado por las provincias de Vizcaya y Guipúzcoa en el País Vasco. Por sus características territoriales y sociales lo hemos considerado como formando un único polo. En su mayoría empresas vinculadas a la tradición de industria pesada industrial y servicios técnicos. En su proceso de declive empresarial relativo no debemos dejar de considerar el lastre que representa el terrorismo de ETA.

El resto del territorio. El restante $27 \%$ de las grandes empresas se reparte de forma diversa por el resto del territorio español, incluidos los restantes enclaves metropolitanos. En ellos predominan las relaciones con los factores productivos territoriales, la tradición para las actividades industriales y la articulación territorial de mercados regionales específicos para los servicios, así como la expansión en los últimos años del turismo vinculado a las características del territorio en las zonas de recepción.

Es interesante resaltar cómo a escala regional se articula un sistema empresarial potente dentro del grupo de las grandes empresas en España y que se organiza sobre la base de satisfacer de forma cuasimonopólica algunas de sus necesidades territoriales. El caso más evidente queda representado por las empresas de distribución de productos a las farmacias y a los hospitales de ámbito regional. Ellas aportan una proporción importante de empresas presentes en el ranking fuera de las grandes metrópolis y localizadas en los centros regionales.

\section{Actividades con vinculación territorial a los recursos físicos o al mercado}

Lo que se detecta al abordar el análisis desde la perspectiva de la actividad es que debe procederse a una distinción sobre la base de la lógica de la organización de la gran empresa según el modelo compacto o el modelo multiplanta.

Ello marcará dos grandes tendencias. Aquellas empresas en que se vincula centro de decisión y centro de producción (o por lo menos el centro de producción principal, aun cuando puedan disponer de otros centros productivos distribuidos territorialmente) donde el factor dominante de localización lo será en función de las necesidades del centro productivo. $Y$ aquellas empresas donde la preferencia se basa en localizar el centro de decisión en relación territorial con factores externos, como puede ser la proximidad a un centro de decisión económico y/o político o la proximidad a otros centros direccionales de un cluster productivo.

$\mathrm{Al}$ analizar las lógicas de localización de la actividad productiva relacionada con los recursos productivos propios de un territorio pueden formularse dos grandes tipos de vinculación territorial: 1) Una vinculación necesaria en relación a la existencia de las primeras materias o a suelo como medio de producción, tanto si son actividades industriales o de servicios (agroindustria, turismo) como si lo son de distribución-comercialización de este tipo de producción hacia mercados externos. 2) Actividades vinculadas al territorio como mercado a escala regional, donde los servicios se localizan como centros de distribución o comercialización de productos externos dirigidos a un mercado limitado a su área circundante (mercado regional).

Por su propia vinculación a los factores productivos territoriales las actividades industriales se hallan dispersas en mayor grado por el territorio, especialmente la actividad minera y la industria agroalimentaria. 
La localización por vinculación territorial muestra una clara tendencia a una dispersión territorial menos centralizada que para el conjunto total, haciendo aparecer municipios relativamente pequeños, sobre todo para las actividades industriales relacionadas con el medio físico, o aprovechando el papel de las capitales de provincia para las actividades de distribución y comercialización para el mercado regional.

En la gran mayoría de estos casos a cada localización le corresponde una empresa monoplanta, donde coincide actividad directiva y actividad productiva.

Como es lógico deducir, los grandes centros metropolitanos (Madrid y Barcelona) son, proporcionalmente, las áreas en que menor peso tienen las empresas ligadas al territorio, sobre todo en Madrid, donde sólo representan el 6,2\%, y en Barcelona el 9,8\%. En estos casos se trata de empresas multiplanta que separan funciones directivas que se vinculan a economías de urbanización de las funciones productivas vinculadas al territorio.

\section{La localización del poder primario y del poder secundario}

$\mathrm{Al}$ introducir el análisis comparado de un territorio que hemos denominado secundario, se busca poder distinguir entre las implantaciones derivadas de las decisiones de creación de empresa desde el territorio de aquellas que responden a la implantación de actividades subsidiarias dependientes ${ }^{9}$ de decisiones adoptadas en otros países, bajo la fórmula que denominaremos como Implantación Multinacional Directa (IMD).

\footnotetext{
9 Se trata en sentido estricto de empresas jurídicas que se constituyen como tales para poder actuar en un país determinado, pero no representan en sí mismas empresas económicas por cuanto no son ni una unidad de gestión ni una unidad de propiedad. La gestión es subsidiaria de las decisiones de la sede central, con independencia del grado de autonomía bajo el que pueda estar organizada la empresa subsidiaria. La propiedad tampoco pertenece a la empresa jurídica, aun cuando puedan darse muy diversas fórmulas de combinaciones accionariales; el hecho más significativo es que ninguna de ellas cotiza en bolsa, cuando sí lo hace la empresa matriz.
}

Desde esta óptica, no nos interesa tanto el grado de dominio del capital extranjero ${ }^{10}$ sobre el sistema empresarial como el momento y las circunstancias de la toma de decisión de localizar la sede de la empresa subsidiaria.

\section{El origen de la localización por creación de empresa o por Implantación Multinacional Directa (IMD)}

Podemos distinguir tres situaciones accionariales en el momento presente: 1) Empresas creadas en el territorio por capitales locales y donde todavía se mantiene el control local (aun cuando en numerosos casos puedan haber internacionalizado su capital). 2) Empresas que en origen fueron creadas desde el territorio pero que en la actualidad se ha perdido el control local (la tendencia en este grupo ha evolucionado en los últimos decenios hacia el control al cien por ciento por parte de capitales extranjeros; en numerosos casos han sido absorbidas por empresas multinacionales que las han integrado como subsidiarias a su red mundial). Ambos grupos los consideraremos como empresas de origen local (EOL) desde el punto de vista de los factores que originaron su localización. 3) Por último, consideramos las empresas IMD como aquellas que han penetrado en el país como decisión directa de la sede central, creándose ex nuovo la estructura jurídica empresarial en el nuevo territorio y que, por tanto, han decidido desde el primer momento cuál sería el lugar adecuado según su estrategia empresarial.

El Cuadro 7 muestra el papel de los entornos metropolitanos ante estos dos procesos de creación de empresas y de localización de las sedes sociales, donde el 30\% lo constituyen empresas IMD y el $70 \%$ empresas con origen local (EOL) en su localización.

Se pone de manifiesto con toda claridad cómo las grandes metrópolis constituyen el foco de

10 La presencia del capital extranjero en las grandes empresas en España supera el 55\% de empresas, estando el $40 \%$ bajo control absoluto al cien por ciento y $5 \%$ bajo control mayoritario superior al 50\% del capital. Se trata pues de un factor importante en el sistema empresarial. En su conjunto esta presencia se hace más acusada en las actividades industriales (62\%) que en el conjunto de los servicios (53\%), siendo escasa en el sector construcción (7\%). 
Cuadro 7. Localización de las grandes empresas en España según su origen de creación multinacional o local (2004)

\begin{tabular}{|c|c|c|c|c|c|c|}
\hline \multirow[b]{2}{*}{ Aglomeraciones } & \multicolumn{3}{|c|}{$\mathrm{N}^{\circ}$ de empresas } & \multicolumn{3}{|c|}{ Distribución \% } \\
\hline & $\begin{array}{l}\text { Implantación } \\
\text { multinacinal } \\
\text { directa (IMD) }\end{array}$ & $\begin{array}{c}\text { Grandes } \\
\text { empresas de } \\
\text { origen local } \\
\text { (EOL) }\end{array}$ & Total & $\begin{array}{c}\text { Implantación } \\
\text { multinacinal } \\
\text { directa (IMD) }\end{array}$ & $\begin{array}{l}\text { Grandes } \\
\text { empresas de } \\
\text { origen local } \\
\text { (EOL) }\end{array}$ & Total \\
\hline Madrid & 183 & 267 & 450 & 61,0 & 38,1 & 45,0 \\
\hline Barcelona & 81 & 166 & 247 & 27,0 & 23,7 & 24,7 \\
\hline Madrid+Barcelona & 264 & 433 & 697 & 88,0 & 61,9 & 69,7 \\
\hline Bilbao-San Sebastian & 5 & 44 & 49 & 1,7 & 6,3 & $\overline{4,9}$ \\
\hline Valencia & 3 & 23 & 26 & 1,0 & 3,3 & 2,6 \\
\hline Sevilla & 2 & 18 & 20 & 0,7 & 2,6 & 2,0 \\
\hline Zaragoza & 4 & 13 & 17 & 1,3 & 1,9 & 1,7 \\
\hline Málaga & 0 & 7 & 7 & 0,0 & 1,0 & 0,7 \\
\hline RM secundarias & 14 & 105 & 119 & 4,7 & 15,0 & 11,9 \\
\hline $\begin{array}{l}\text { Total localización no } \\
\text { metropolitana }\end{array}$ & 22 & 162 & 184 & 7,3 & 23,1 & 18,4 \\
\hline Total & 300 & 700 & 1000 & 100 & 100 & 100 \\
\hline
\end{tabular}

Fuente. Elaboración propia sobre datos de Fomento de la Producción y fuentes diversas

atracción por parte de las empresas multinacionales al efectuar una inversión territorial directa ex nuovo. Ello se suma a la importante capacidad de localización que las dos grandes metrópolis han ejercido sobre los capitales locales que han alcanzado a constituir grandes empresas (casi el $62 \%$ de atracción en el inicio de su actividad). En conjunto, el poder de atracción y concentración de las metrópolis aumenta hasta casi el 70\%, superado por el $88 \%$ para las IMD que han elegido directamente la localización metropolitana.

Es muy interesante constatar que la capacidad de atracción para las IMD aumenta a medida que es mayor la potencia metropolitana. Así Madrid, como primer núcleo, muestra un diferencial de atracción entre empresas de origen local y de origen multinacional directo de 23 puntos; Barcelona disminuye hasta unos 3 puntos. Por debajo de este nivel de metropolización la capacidad de atracción se hace negativa: menos 10 puntos en las restantes áreas metropolitanas consideradas y menos 16 puntos para el resto del territorio no metropolitano. Ello se concreta en 183 empresas en Madrid, 81 en Barcelona, 14 en el resto de aglomeraciones metropolitanas y 22 en núcleos de inferior tamaño.

Sectorialmente, la IMD muestra dos modelos de comportamiento. La actividad industrial, que representa un $46 \%$ (136), se concentra a partes iguales en Madrid (58) y Barcelona (51), dejando un mínimo (18) para el resto del territorio. El comportamiento de los servicios se vincula de forma casi exclusiva al hecho metropolitano, ya que de las 160 empresas, 124 lo hacen en Madrid, 29 en Barcelona, 4 en el resto metropolitano y sólo 3 dispersas.

Los factores que explican la mayor dispersión industrial aparecen vinculados bien a la existencia de lo que podríamos denominar clusters de especialización industrial preexistentes o a ser territorios en los que se aplicaron políticas económicas de incentivo. Para el caso español la política de los polos de desarrollo de los años 1960-70 ha tenido incidencia en ciudades como Zaragoza, Valladolid, Vigo, Huelva o Tarragona ${ }^{11}$. Vigo y Valladolid acogieron en su momento dos factorías de montaje de automóviles: Citroën en Vigo y Renault en Valladolid. Otras políticas de incentivo fueron la respuesta a situaciones de crisis territorial, como sería el caso de Cádiz.

En cuanto al papel de los clusters de especialización como factor de atracción, lo observamos en Valencia, zona de antigua industrialización, que fue considerada idónea para ser elegida como lo-

\footnotetext{
11 Huelva y Tarragona se especializaron en el sector petroquímico y acogen la sede y planta de Tioxide Europa y Basf.
} 
calización de la planta de ensamblaje Ford. Por su parte, en Zaragoza se configuró sobre la dinámica del polo un potente tejido industrial metalúrgico que creó las condiciones para atraer años más tarde la planta de Opel. La apuesta de Volkswagen por Navarra ha actuado de igual forma. La capacidad de inducción empresarial de estas potentes actividades ha motivado la subsiguiente potenciación atractiva de importantes empresas de componentes del sector del automóvil ${ }^{12}$.

En todos estos casos la sede empresarial coincide con el centro productivo, lo que se explica por la mayor importancia de su integración vertical con la empresa matriz y su escasa necesidad de integrarse horizontalmente en un entorno de aportación de economías de urbanización y sólo con aquellas relacionadas con la actividad sectorial, en este caso con el montaje de automóviles.

Un tercer frente de desvinculación metropolitana lo muestran aquellas empresas vinculadas a los recursos naturales o actividades especializadas de servicios, como puede ser el turismo ${ }^{13}$.

Por último podemos considerar un factor de localización no metropolitana la relación a redes de transporte en las empresas de distribución o logística ${ }^{14}$.

El otro eje estratégico de localización afecta a la diferenciación entre actividades de producción (en numerosos casos orientados al mercado internacional, preferentemente europeo) y las actividades de comercialización y de servicios sobre el mercado y dirigidas exclusivamente al mercado interior español.

En el primer eje ya hemos visto que la localización aparece más ligada a las áreas de antigua o más reciente industrialización, donde en muchos

12 Faurencia, Johnsons Control Automotive, Mann+Hummel, Arvinmeritor Emissions Thecnologies y Delphi Automotive corresponden a empresas de este tipo incluidas en nuestro ranking. En Cádiz se encuentra Cadiz Electrónica (Ford) y Delphi Technologies.

13 Los casos de este apartado son: Hero (Murcia), Texaco (Canarias) y Futura Internacional Airways (Mallorca).

14 Schlecker, Kellogs y Adidas sobre el eje de autopistas en Tarragona y Zaragoza. casos sede y centro productivo coinciden, como acabamos de ver.

En el segundo caso, la localización de los centros de comercialización elige prioritariamente Madrid, donde el centralismo sobre el que se organiza el territorio español aporta mayores economías en su relación con el mercado interior. Por su parte los servicios se ven favorecidos desde la misma capital por su potencia y poder como centro de decisiones políticas y económicas. La debilidad ya señalada de Barcelona al respecto la sitúa en un segundo plano (29 empresas frente a las 124 de Madrid); igual que ocurre con el resto del territorio.

\section{Síntesis del modelo de localización metro- politana}

El objetivo principal de este trabajo ha sido detectar algunos de los factores socioterritoriales que intervienen en la localización de las sedes sociales de las grandes empresas, sobre la hipótesis de la importancia que tienen los entornos metropolitanos.

En esta línea, y como conclusión, efectuemos una síntesis de los comportamientos que hemos detectado, tanto a la escala mundial de las sedes de las grandes empresas mundiales como a la escala secundaria en la relación entre centros de promoción local y centros de implantación directa subsidiaria de empresas extranjeras cuando se asientan en estos territorios secundarios.

Existe una clara correlación entre el volumen de empresas localizadas y concentradas en un territorio con la dimensión de su aglomeración urbana (coeficiente de correlación de 0,91 para el caso español). El factor poblacional es un indicador indirecto del mayor volumen de capacidad productiva y, consecuentemente, empresarial.

- Los entornos metropolitanos se configuran como los ámbitos territoriales de concentración de las sedes (el $87 \%$ para las grandes empresas multinacionales y el $93 \%$ para el caso español).

Por encima del poder metropolitano se sitúa el factor capitalidad como poder en la locali- 
zación de sedes. Ello queda reflejado en que más del $43 \%$ de las empresas se localizan en las capitales de los Estados.

Aun cuando este factor es dominante aparece un limitado número de países donde esta norma no se cumple: en 3 países sobre 32 (9\%) la capital no atrae sedes y en otros 3 concentra menos del $50 \%$, mientras que en el $83 \%$ restante la capital es dominante y en casi el 38\% de éstas todas las empresas están concentradas en la capital.

- La mayor capacidad de atracción de los centros metropolitanos hace que también se localicen las inversiones externas procedentes de capitales extranjeros. Ello se manifiesta con claridad en las decisiones de las empresas multinacionales localizadas ex nuovo (lo que hemos denominado inversión multinacional directa) que de forma preferente buscan aprovechar las economías y ventajas que ofrecen este tipo de entornos territoriales.

- $\quad$ El factor explicativo se fundamenta en las potencialidades y oportunidades territoriales que representan las economías urbanas -de aglomeración, concentración y escala- que aportan los núcleos de mayor población y especialmente las zonas metropolitanas.

Se muestran como condiciones preferentes de localización el potencial de poder político y los servicios a las empresas.

Lo que realmente distingue un centro urbano de una zona metropolitana es que el mayor volumen empresarial se corresponde con una mayor diversificación de actividades (economías de aglomeración) y con un mayor volumen de potenciales empresas-clientes que genera una masa crítica de esta diversidad de actividades (economías de escala empresarial).

Por todo ello, los grandes centros metropolitanos aportan un plus de concentración sobre la base de estas economías. Es decir, las economías de aglomeración incorporan una realimentación positiva de forma que al aumentar las empresas aumentan las actividades dependientes en volumen, calidad y diversificación; y al aumentar éstas se cons- tituyen, como economía de escala, en factor de atracción para nuevas sedes, que verán facilitada de esta forma su labor de gestión.

Los núcleos urbanos de segundo nivel muestran una de sus potencialidades en acoger empresas vinculadas al territorio por la vía de la explotación del mercado regional que las envuelve. De ahí la presencia de actividades de intermediación comercial o de redes regionales de comercio al por menor.

Los procesos metropolitanos no se comportan de forma idéntica. Se muestra como elemento diferenciador las características de las relaciones de poder que cada uno de ellos integra. Así es como cabe distinguir entre poder político y poder económico, y sus respectivos componentes socio-relacionales, que corresponden a cada zona metropolitana, los cuales se constituyen a su vez también como factor multiplicador de la capacidad de atracción.

El factor metropolitano se refuerza con el factor capitalidad política. De las 119 aglomeraciones con EMN, 28 son capital de Estado $(23,5 \%)$ que reflejan su poder concentrando más del $43 \%$ de estas empresas. El poder político viene representado tanto por su aplicación a la escala interior del Estado (factor capitalidad) como en su capacidad de relación con el espacio exterior (por su importancia en las relaciones geopolíticas a escala internacional, pero también en su dotación infraestructural, como puede serlo la dotación en aeropuertos internacionales).

El poder económico, en el proceso de crecimiento de estas empresas desde su creación hasta el volumen e importancia actuales, ha actuado como efecto sobre el propio proceso de metropolización de los territorios en los que se constituyó. Son escasas las grandes empresas actuales consideradas que no han dado origen a una aglomeración metropolitana. Solamente 9 industrias no han originado procesos metropolizadores.

La concentración es a su vez causa de una realimentación sistémica sobre el crecimiento de estas aglomeraciones. 
Por estar organizadas estas empresas bajo el modelo multiplanta (en fabricación o en oferta de servicios) o por corresponder a actividades internacionales, la sede social puede encontrarse separada territorialmente de los centros productivos. Ello es un factor complementario a la posibilidad de localización de estas sedes en entornos urbanos y metropolitanos, donde se vea potenciada la componente estratégica y de política empresarial, al disponer de entornos donde las economías de aglomeración, con la consiguiente aglomeración de poder político, económico y potencial social-relacional, refuerce el componente de gestión frente al componente de producción, que no participa directamente de estas estrategias.

Podemos llegar a la conclusión de que para aumentar su capacidad de atracción aquellos entornos territoriales y metropolitanos con bajo o nulo poder político deberían reforzar las potencialidades de la especialización que permitiesen constituir economías de aglomeración y concentración especializadas de alto potencial y capacidad.

Del caso español podemos apuntar que la metrópolis que concentra el poder político, con sus vinculaciones internacionales (Madrid), ejerce una potente capacidad de atracción para localizar en ella tanto sedes de empresas nacionales como de empresas multinacionales (IMD). Las áreas metropolitanas que superan un umbral de poder económico y de vinculaciones internacionales (Barcelona) mantienen su plus histórico de capacidad de concentración de forma más o menos estable. Mientras que las áreas metropolitanas de menor poder económico y menor capacidad de vinculación internacional (Bilbao, Valencia, Sevilla) ven perder su plus histórico de localización.

Por último, políticas de intervención del Estado sobre el territorio (por ejemplo, los polos de desarrollo en el caso español, o la potenciación de eventos internacionales) pueden propiciar la dinámica de aglomeración urbana, como se ha constatado en Sevilla, Zaragoza o Valencia.
Todo ello lleva a la conclusión final de que la concentración territorial de poder político, poder económico y vinculación internacional -por este orden de importancia-, son tres de los factores fundamentales que explican las decisiones de localización de las sedes sociales y centros decisionales de las grandes empresas, sean nacionales o extranjeras, condiciones que se dan en las áreas metropolitanas.

A partir del caso español, como complemento del comportamiento de las grandes empresas mundiales, hemos alcanzado una primera aproximación a la importancia del hecho metropolitano como base territorial de asentamiento de las sedes de las grandes empresas. Para poder generalizar estas conclusiones sería preciso disponer de mayor número de estudios de caso de territorios secundarios, lo que sería interesante que pudiera efectuarse para alcanzar una generalización de las pautas de comportamiento de localización definitivas.

\section{Referencias bibliográficas}

Alonso Villar, O. (1997). El análisis económico de los procesos de urbanización. Vigo: Universidad de Vigo. Recuperado el 2 de mayo de 2006, de http://dialnet.unirioja.es/.

Arita, T. \& Mccann, Ph. (2004). A comparison of industrial location behaviour within the US and European Semicondictor Industries. European Regional Science Association (ERSA).

Evans, A. W. (1973). The location of the headquarters of industrial companies. Urban Studies, 10, 3, 387-395.

Fomento de la Producción (2005). Las 2.000 mayores empresas españolas. Barcelona: Fomento de la Producción.

Fortune (2006). Fortune Global 500 (2005). Recuperado el 2 de mayo de 2006, de http://money. cnn.com/magazines/fortune/global500/2006/ industries/.

Holloway, S. \& Wheeler, J. (1991). Corporate headquarters relocation and changes in metropolitan corporate dominance, 1980-87. Economic Geography, 67, 1, 55-74.

Klier, T. H. \& Testa, W. (2001). Headquarters wanted: principals only need apply. Chicago Fed Letter, Federal Reserve Bank of Chicago, 167 a.

Klier, T. H. (2006). Where the headquarters are: location patterns of large public companies, 
1990-2000. Economic Development Quarterly, 20, 2, 117-128.

Martínez Estevez, A. (2002). La concentració del poder econòmic. València: Universitat de València. Recuperado el 2 de mayo de 2006, de http://books.google.es.

Mascarilla Miro, O. (2002). Localización de la actividad económica, movilidad laboral y mercado residencial. Boletín Económico de ICE, $27,35,43-54$.

Méndez, R. (2001). Transformaciones económicas y reorganización territorial en la región metropolitana de Madrid. EURE, 27, 80, 141-162.

Noyelle, T. \& Stanback, T., Jr. (1984). The economic transformation of american cities. Totowa, NJ: Rowman y Allanheld.

Përez, M. (2007). Bailando con los fondos. Barcelona: Dinero La Vanguardia.

Porter, M. E. (1990). La ventaja competitiva de las naciones. Barcelona: Ed. Plaza y Janés.

Quark, A. A. (2007). From global cities to the lands' end: the relocation of corporate headquarters and the new company towns of rural America. Qualitative Sociology, 30, 1, 21-40.

Sánchez, J.-E. (1986). Guerra y dominio del espacio: la guerra interior española de 1936-1939 en su proyección espacial subsiguiente. Anales de Geografía de la Universidad Complutense, 6, 225-249.

(1998). La gran empresa en España. Un proceso de dependencia y concentración. Madrid: Consejo Económico y Social, CES. (2006a). Dépendance et concentration de la grande entreprise en Espagne. En R. Méndez (Ed.), Géographie de l'Espagne (pp. 163-217). París: L'Harmattan.

(2006b). El papel de las áreas metropolitanas y las pautas de localización de las sedes de las grandes empresas. El caso de Barcelona. En C. Carreras \& A. F. A. Carlos (Eds.), Barcelona y Sao Paulo cara a cara. Procesos metropolitanos a la hora de la globalización (pp. 44-64). Mataró: Editorial Davinci.

Sassen, S. (1994). Cities in a world economy. London: Pine Forge/Sage Press.
(1998). Ciudades en la economía global: enfoques teóricos y metodológicos. EURE, $24,71,5-25$.

Shilton. L. \& Stanley, C. (1999). Spatial patterns of headquarters. Journal of Real Estate Research, $17,3,341-364$

Slater, E. (2004). The flickering global city. Journal of World-Systems Research., 10, 3, 590-608.

Taylor, P. (2002). European cities in the world city network. En H. Van Dijk (Ed.), The european metropolis 1920-2000. Conference at the centre of comparative european history, Berlin, Alemania.

Taylor, P. J. \& Lang, R. E. (2005). U.S. cities in the 'world city network'. Washington D. C.: The Brookings Institution.

Van Der Knaap, G. A. \& Wall, R. (2002). Linking scales and urban network development. En Van Dijk, H. (Ed.), The European Metropolis 1920-2000, Conference at The Centre of Comparative European History, Berlin, Alemania.

Vives, X. \& Torrens, Ll. (2004). Estratègies de les àrees metropolitanes europees davant l'ampliació de la Unió Europea. Barcelona: Pla estratègic Metropolità de Barcelona.

Vives, X. (2000). Globalització i localització de l'activitat econòmica: Catalunya i la geografia del poder econòmic. Nota d'Economia, 68, 99-115.

(2002). Centres de decisió empresarial i activitat econòmica: els efectes de la globalització. Barcelona: Generalitat de Catalunya. Departament d'Indústria, Comerç i Turisme.

Wang, D. T. (2005). Multinational corporations (MNCs)' strategic location and the development of financial service hubs in China. Denver: AAG Conference.

Wheeler, J. O. (1987). Fortune firms and the fortunes of their headquarters metropolises. Geografiska Annaler B, 69, 65-72.

(1988). The corporate role of large metropolitan areas in the United States. Growth and Change, 19, 2, 75-86.

Yeung, Y. M. (1997). La geografía en la era de las megaciudades. Revista Internacional de Ciencias Sociales, 151. 